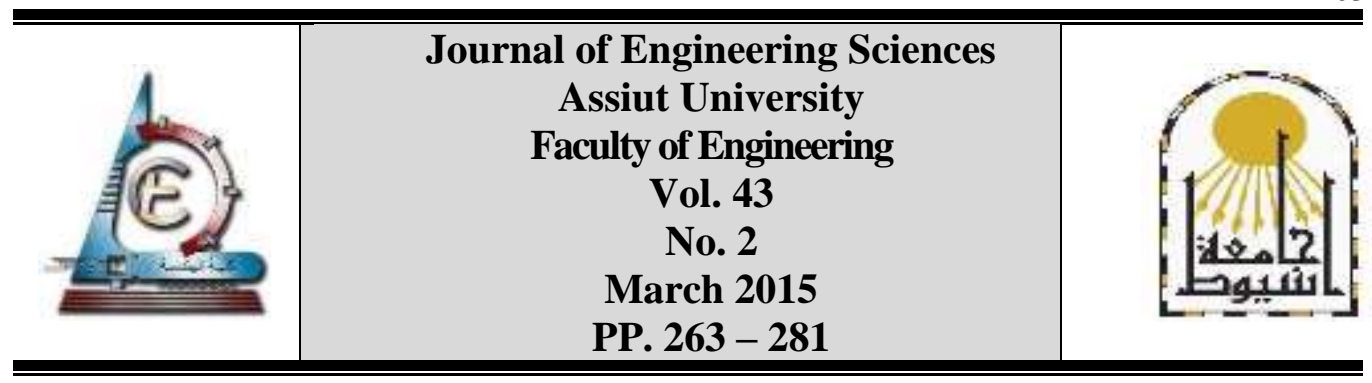

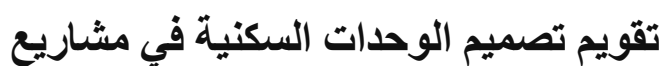

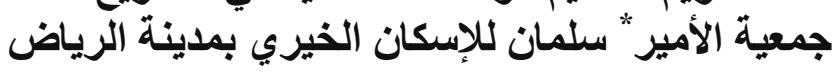

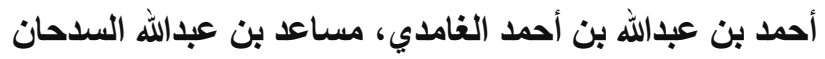
قسم العمارة وعلوم البناء، كلبة العقارة والتخطبط ، جامعة الملك سعود

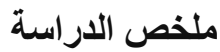

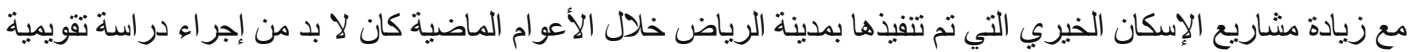

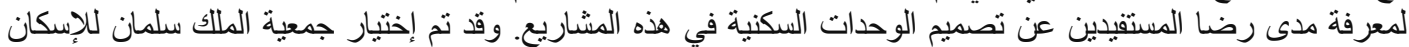

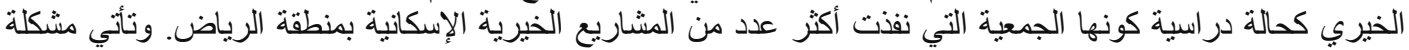

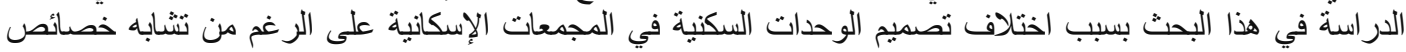

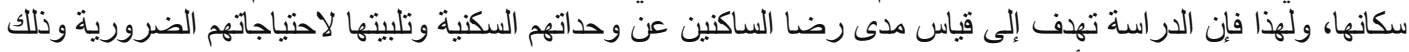
لمعرفة المنطلبات الفر اغية الأساسية التي تؤثر على الرضي الريا لتوفير ها في الوحدات السكنية المستقبلية.

وتم عمل دراسة لقياس رضا المستفيدين عن تصميم الوحدات السكنية من خلال المقارنة بين مشاريع الجمعية في مدينة

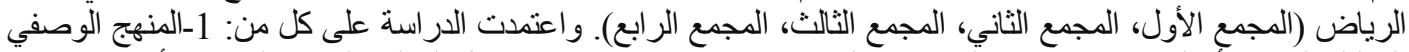

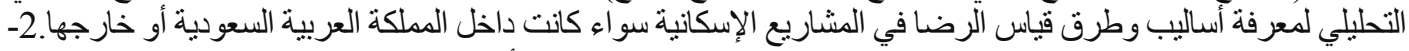

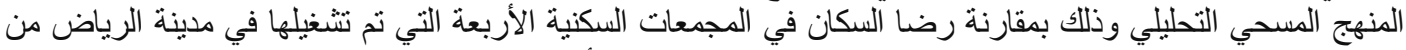

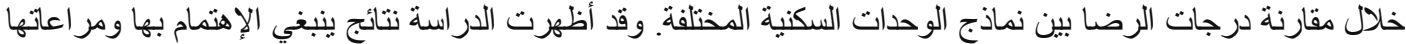

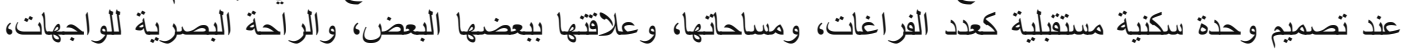

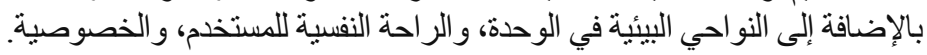

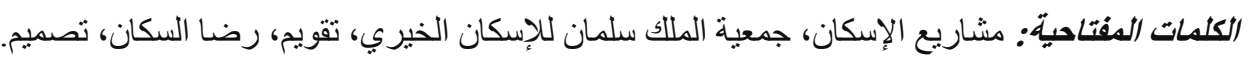

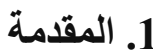

بدأت معاناة المملكة العربية السعودية من مشكلة السكن في السبعينيات الميلاديـة، وتم وضسع استر اتيجية

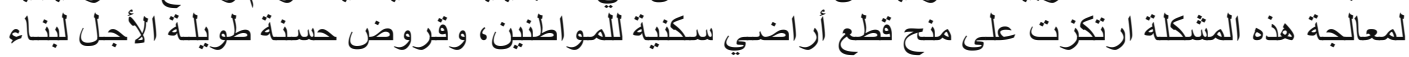

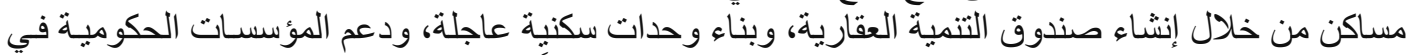

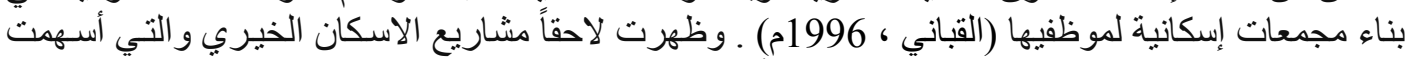

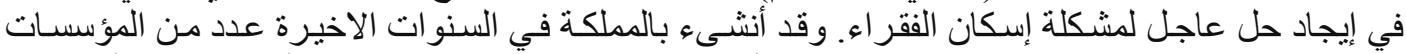

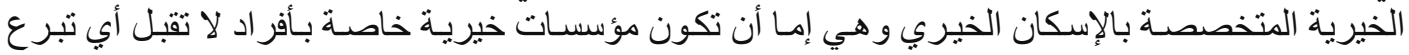

* تأسست جمعيـة الأمير سـلمان للإسـان الخيري في عـام 1997م يوم أن كـان الأمير سـلمان بـن عبدالعزيز أميراً

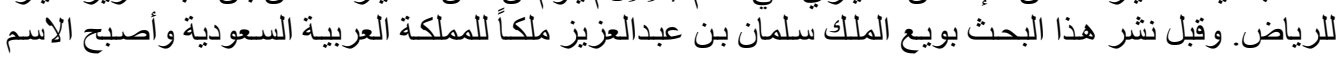
الرسمي للجمعية: جمعية الملك سلمان للإسكان الخيري. 
أحمد بن عبداله بن أحدد الغامدي، مساعد بن عبدالهه السدحان، تقويم تصميم الوحدات السكنية في مشاريع جمعية.

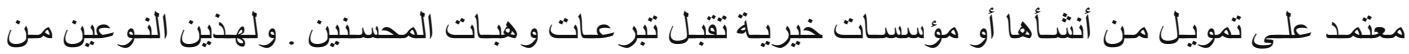

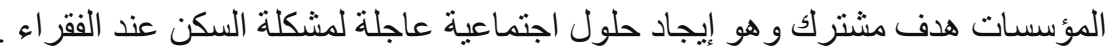

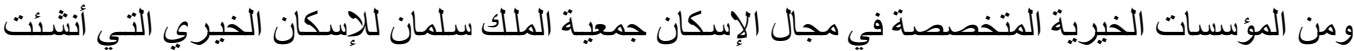

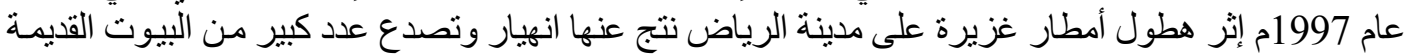

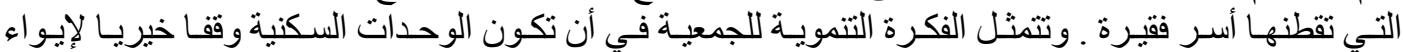

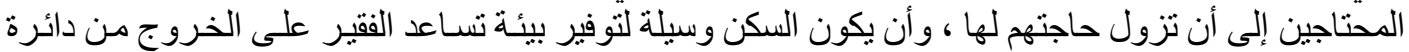
الفقر، وأن يرتبط السكن ببرامج تتموية تعمل على مساعدة الفرد و الأسرة على التحول من معتمدين إلى منتجين .

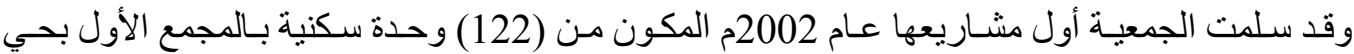

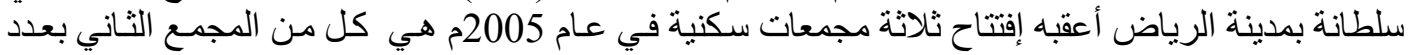

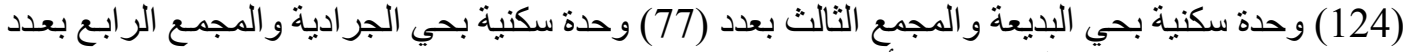

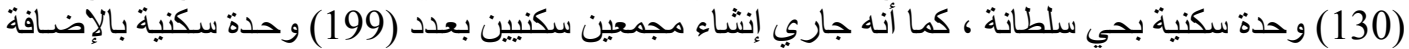

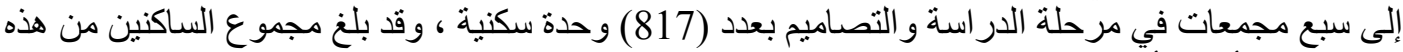
المجمعات الأربعة أكثر من (4000) شخص (إدارة جمعية الملك سلمان ، 2005م).

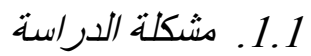

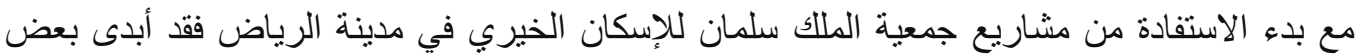

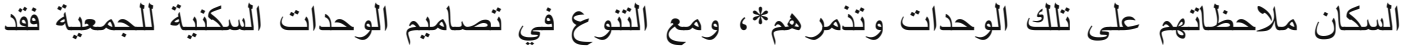
برزت الحاجة لعمل تقويم لرضا الساكنين عن تلك الوحدات الوحات السكنية.

$$
\text { 2.1 2.1 هدف الدر/سة }
$$

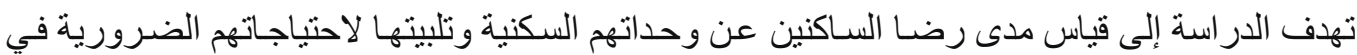

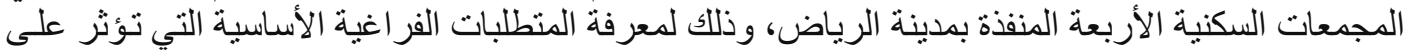

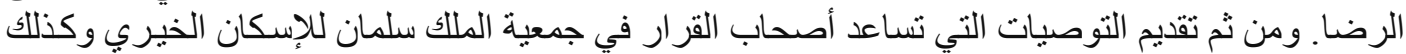
المصمين في تقديم الحلول التصميمية المناسبة للسكان.

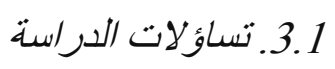

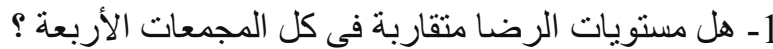
2- هل يو جد إختلاف في معدلات الرضات الرضا بين الوحدات ذات التات النماذج المختلفة ؟

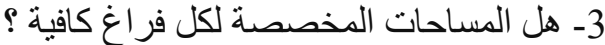

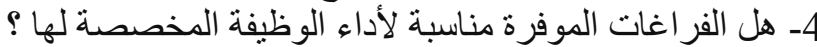
5- هل توزيع العناصر و وعلاقتها ببعضها الباء البعض منو القة مع منطلبات الأسرة ؟ 4.1. منهجية الدراسة

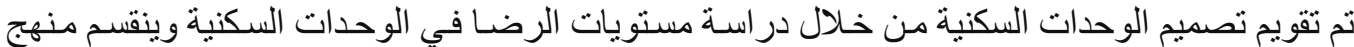

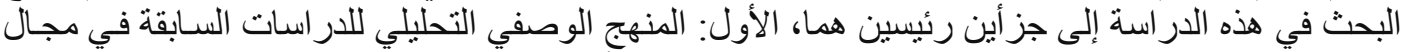

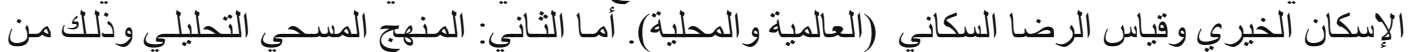

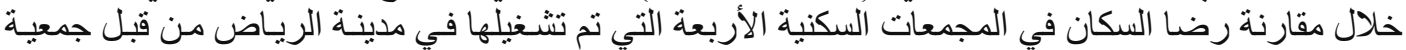

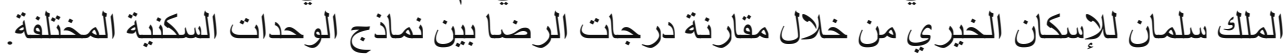
وقد تم الاعتماد على الاستبانة كأداة أساسية في عملية التقويم وقياس الرضا لساكني الوحدات السكنية 
وذللك لصعوبة استخدام أدوات أخرى للحصول على معلومات، حيث لم بسمح للباحثان بزيارة السكان من قبل إدارة الجمعية حفاظاً على خصوصيتهم. وتم تصميم الإستبانة بعد أخذ عدة اعتبار ات لات أهمها:

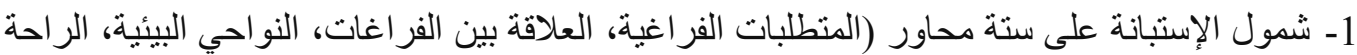

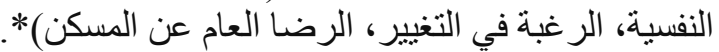

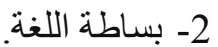

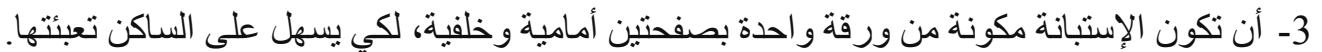

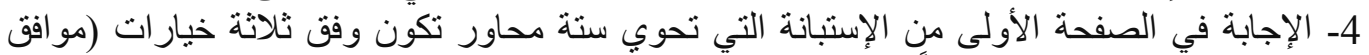

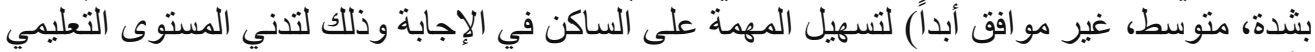

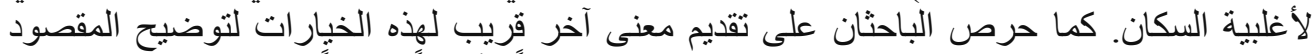

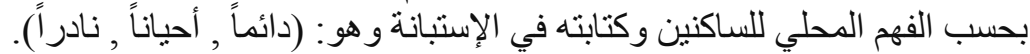

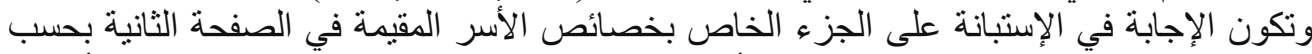

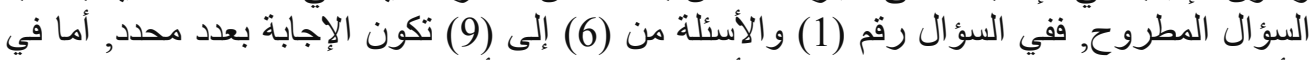

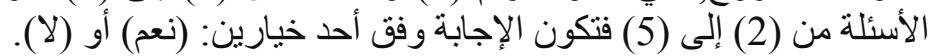

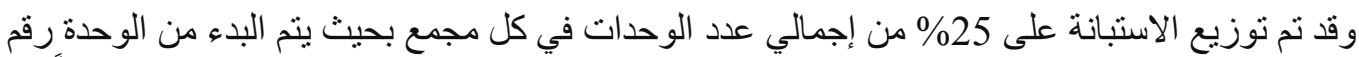

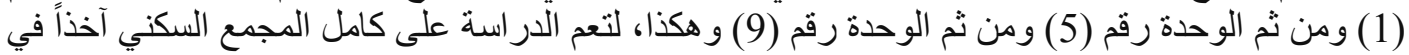

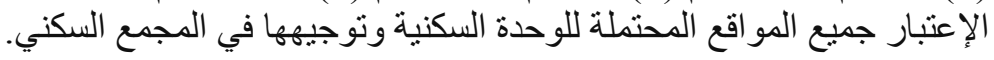

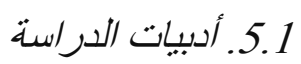

أجريت العديد من الدر اسات داخل المملكة العربية السعودية وخارجها سو اء في تقويم مشاريع الإسكان الخيري

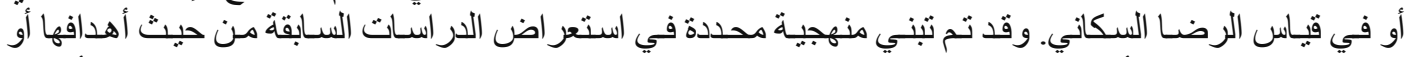

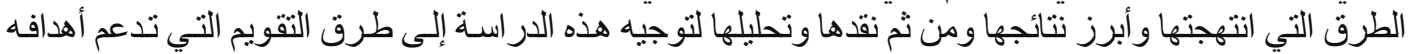

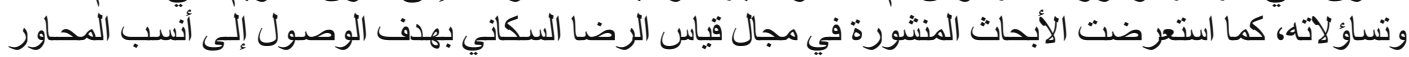

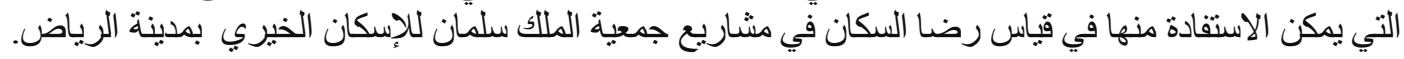

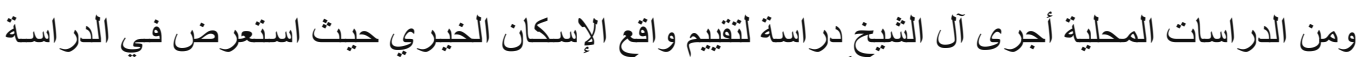

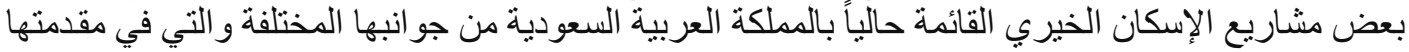

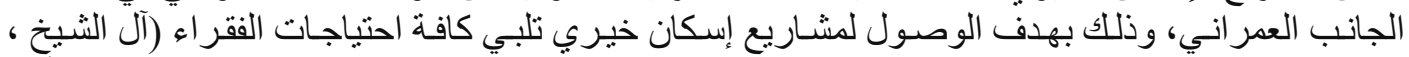

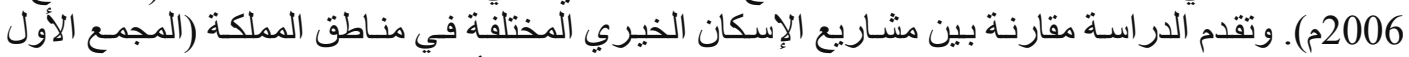

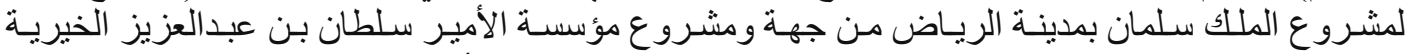

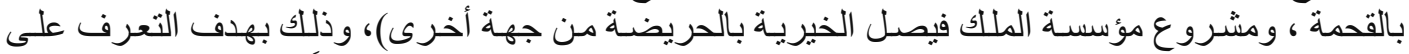

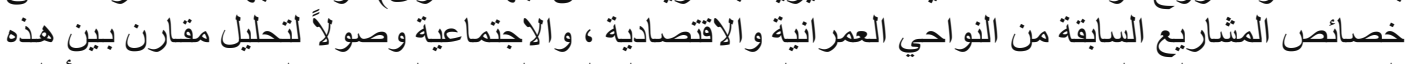

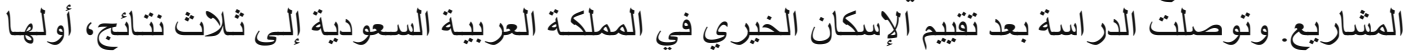

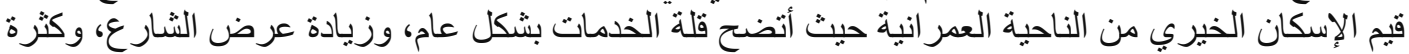

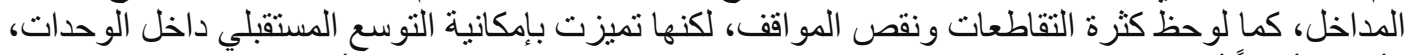

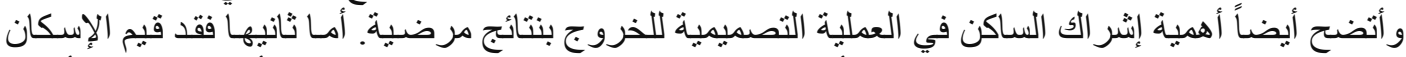

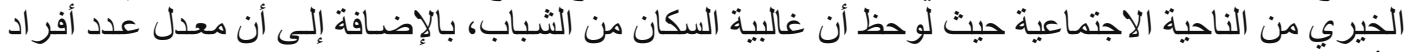

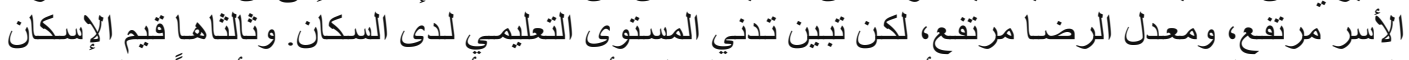

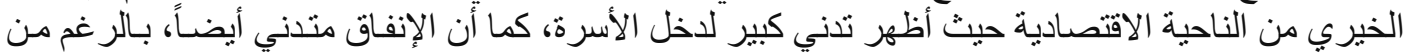

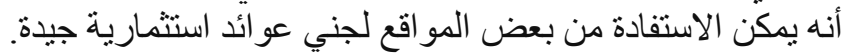

* يوضح البحث لاحقاً سبب إختيار المحاور الستة (المتطلبات الفراغية، العلاقة بين الفراغات، النواحي البيئية، الراحة النفسية، الرغبة في التغيير، الرضأب الرغار العام عن المسكن). 
أحدد بن عب/اله بن أحد الغامدي، مساعد بن عب/لهة السدحان، تقويم تصديم الوحدات السكنبة في مشاريع جمعية.

وحيث أن دراسة آل الثيخ قد أهتمت بالإسكان الخيري على النطاق الواسيع (الجانب العمر اني) إلا أنها

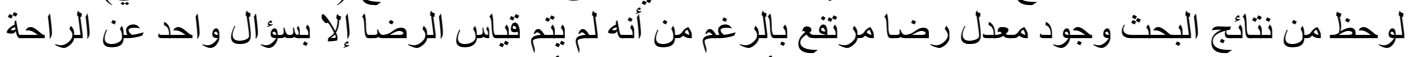

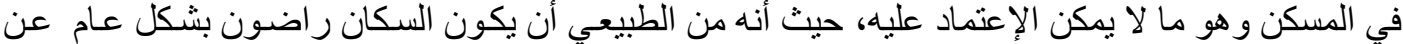
وحداتهم بعد إنتقالهم من مساكن منهارة و عشش إلى منى مساكن جديدة.

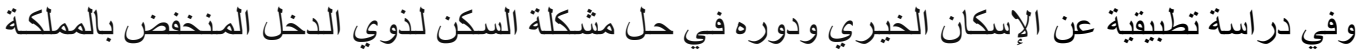

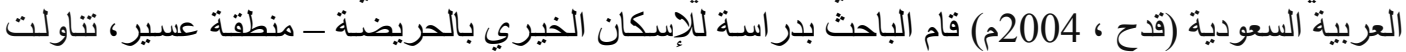
الدر اسة مشكلة الإسكان الخيري لذوي الدخل المنخفض، ولفئات أخرى من سكان المناطق النائية و البعيدة عن

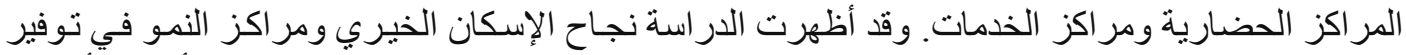

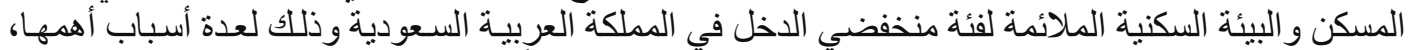

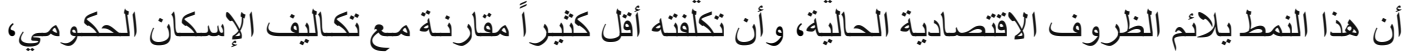

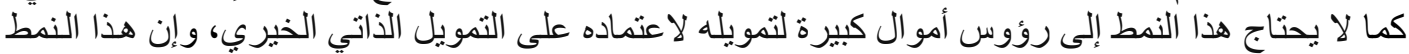

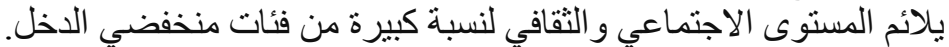

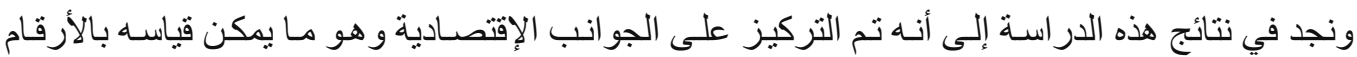

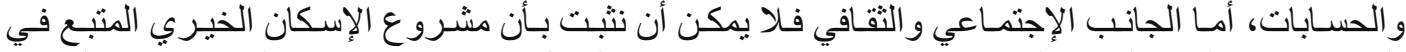

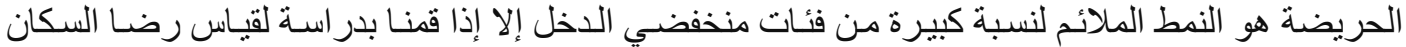
و المقارنة بين أكثر من مشروع منفذ ولهو ما لم ينطرق له البحث.

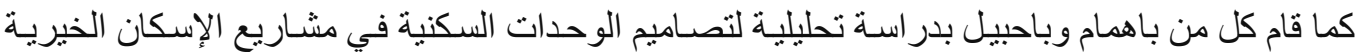

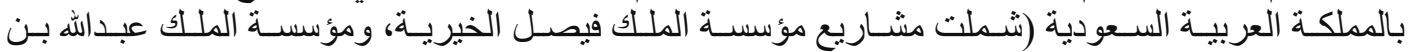

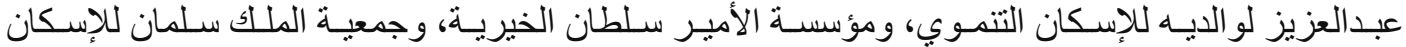

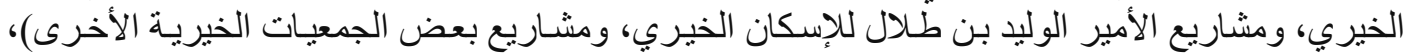

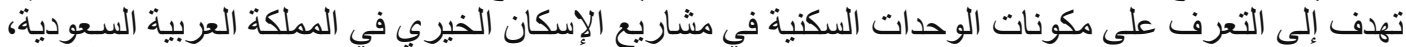

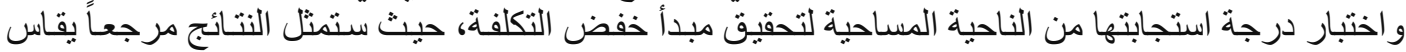

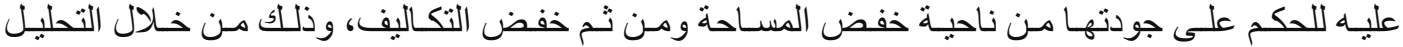

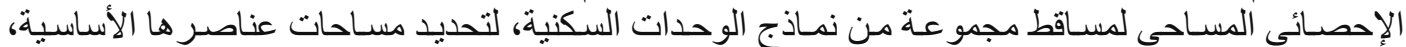

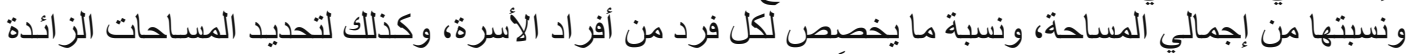

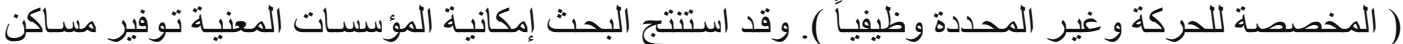

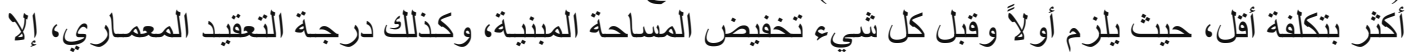

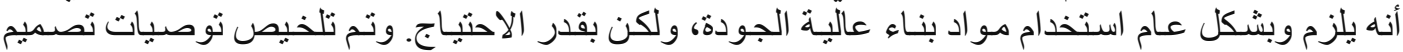

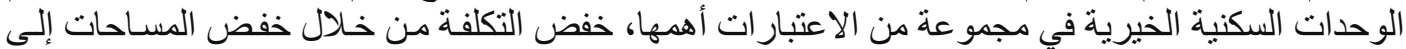

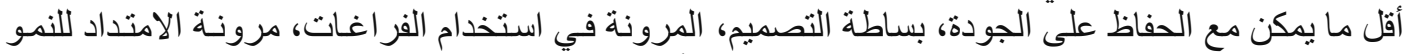
المستقبلي، العناية بالاستدامة البيئية، تقليص الحاجة إلى أعمال الصيانة المعقدة (باهمام وباحبيل ، 2007م).

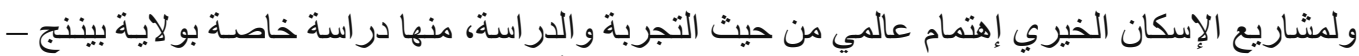

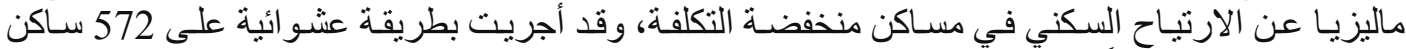

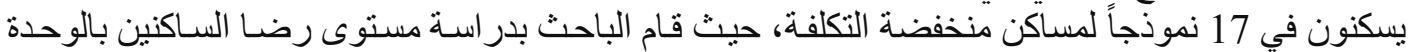
السكنية والأحياء السكنية في المساكن منخفضة التكلفة (Residential and Neighborhood Satisfaction)، ودلت نتائج البحث بصفة عامة على أن للوحدات السكنية والخدمات المنات المنزلية التي أعدها المطورون ارتباح

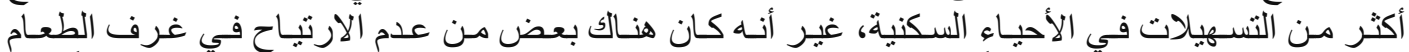

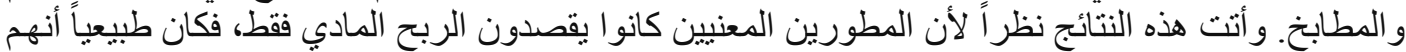

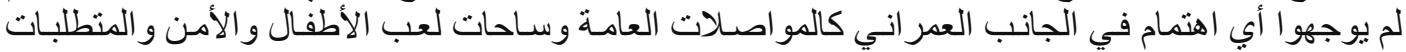

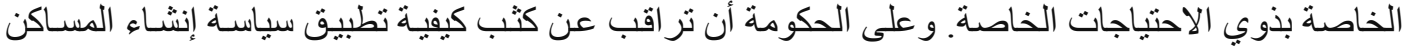
منخفضة التكلفة، وذللك في سبيل رفع نو عية الحياة لسكانها (Ghani , 2007). 
6.1.كيف بقاس الرضا السكاني

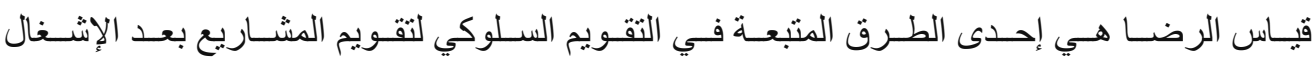

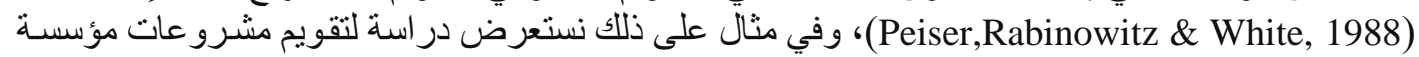

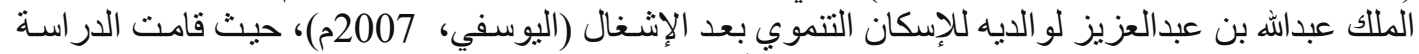

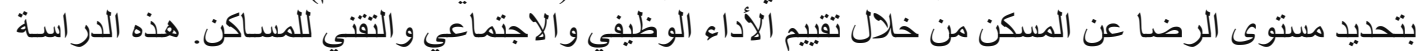

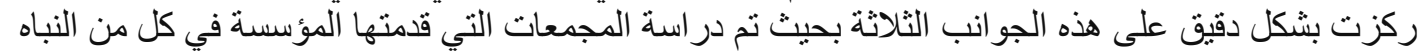

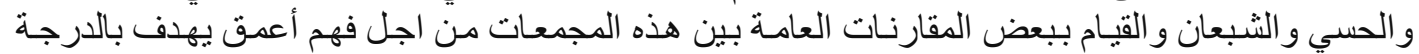

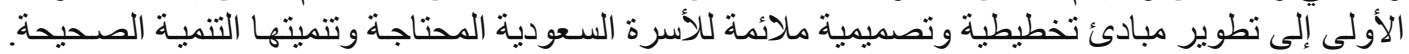

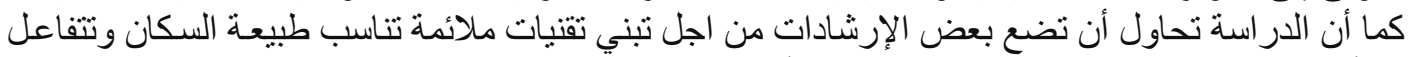

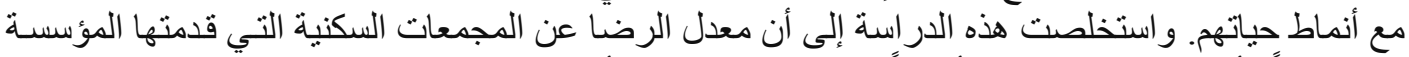

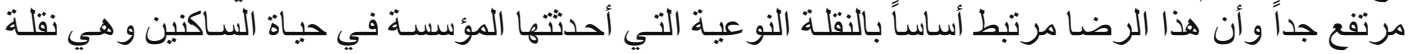

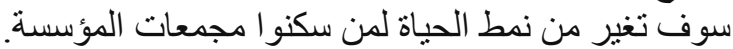

وقد أشـار فر انسيس إلى أن أول سنة من السكن تعتبر فترة العسل (Honeymoon Period) و لا يمكن الإنس

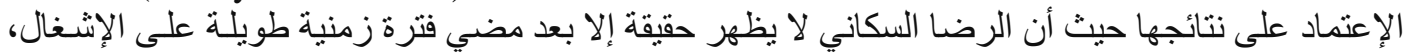

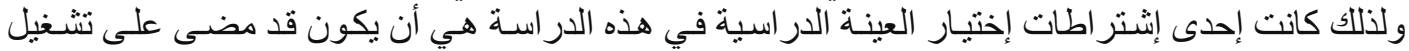

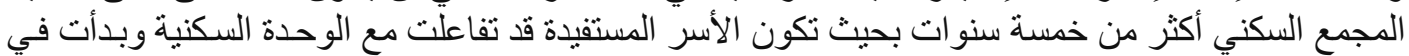
لمس إحتياجاتهم الفعلية خلال هذه الفترة خلز الزمنية (Carp,1975).

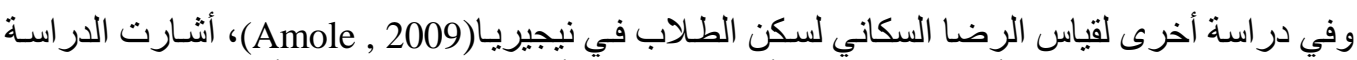

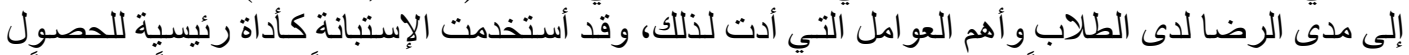

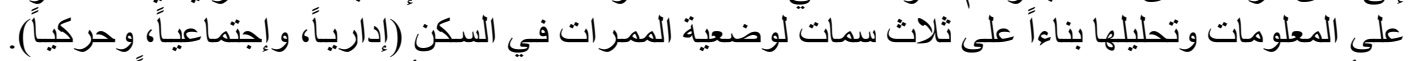

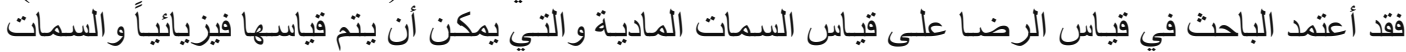

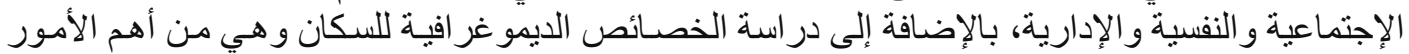

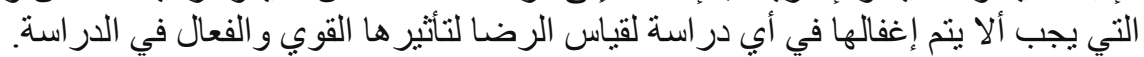

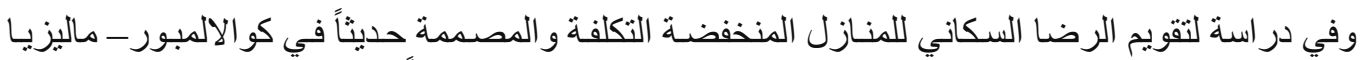

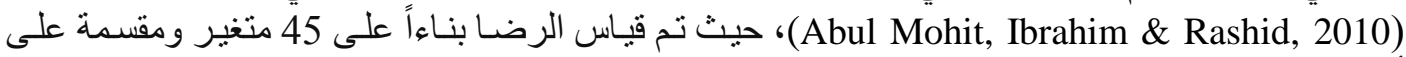

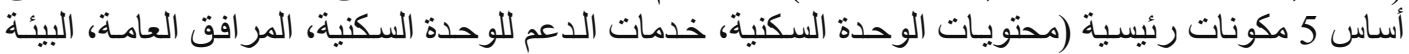

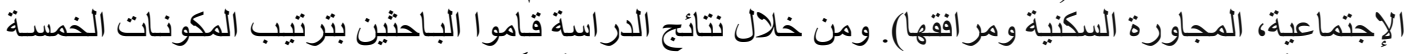

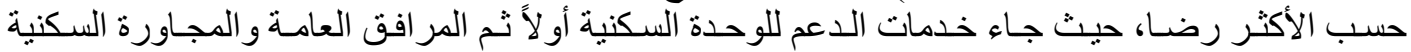
ومر افقها ثم محتويات الوحدة السكنية و البيئة الإجتماعيـة (AbulMohit, Ibrahim \& Rashid, 2010), كمـات لوحظ بأن للجانب الإجتماعي أهمية كبيرة في تغذية مخرجات الإنة وتحليل الدر اسة.

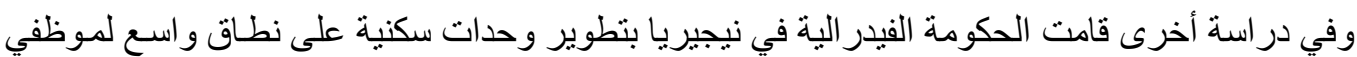

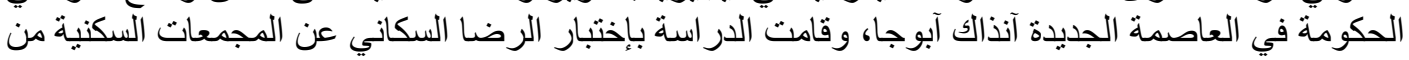

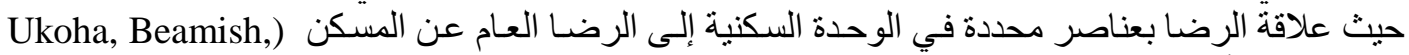

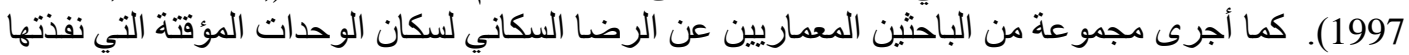

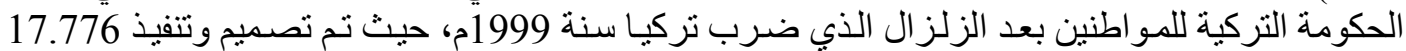

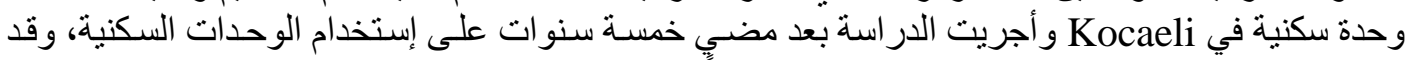

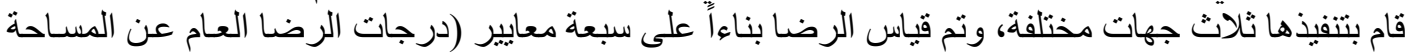

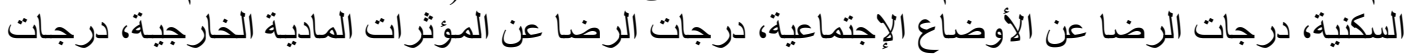

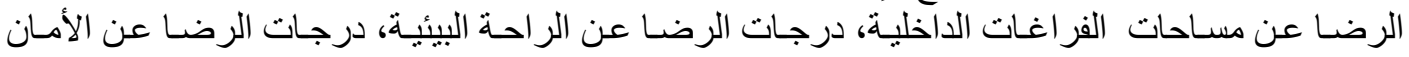

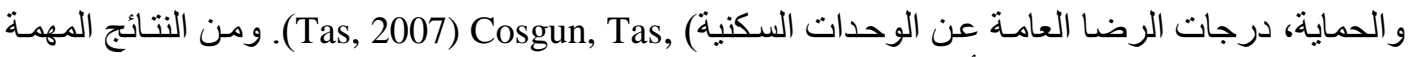
في در اسة Altas و Ozsoy هي أن درجات الرضا السكني تنتاقص مع الزمن وفق تغير الإحتياجات الخاصـة 
أحدد بن عبداله بن أحدد الغامدي، مساعد بن عبد/له السدحان، تقويم تصديم الوحدات السكنية في مشاريع جمعية..

بكل فراغ (Ozsoy, Altas, 1998)، ولذلك نجد أن المستخدمين يحصلون على رضـا أعلى عند تمكنهم من أن أنس

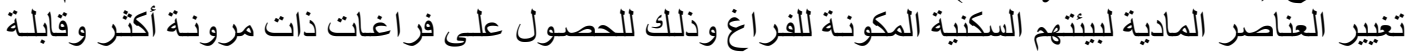
للتأقلم مع مرور الزمن.

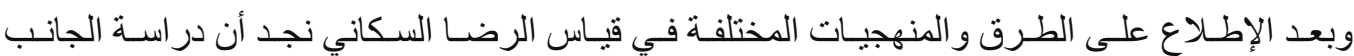

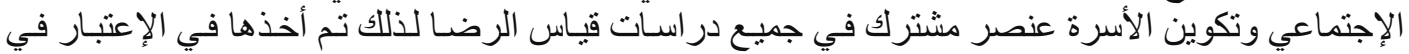

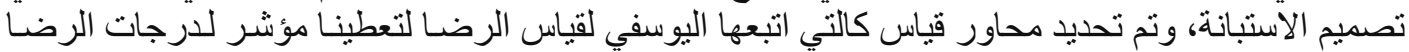

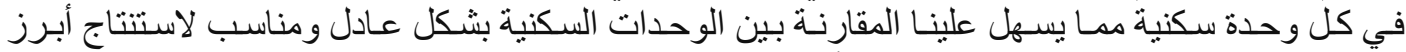

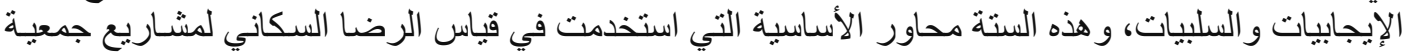

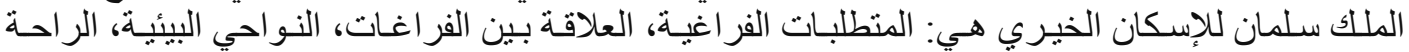

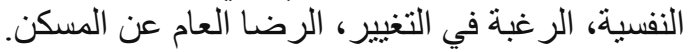

\section{2. عينة الدراسة}

تمثل عينة الدر اسة جميع المجمعات السكنية التي قامت جمعية الملك سلمان للإِسكان الخيري بتنفيذها في

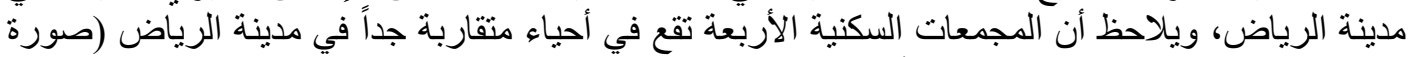

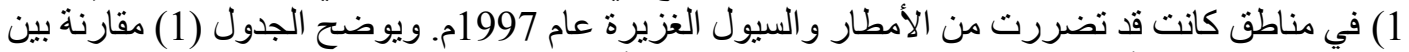

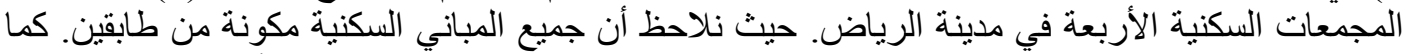

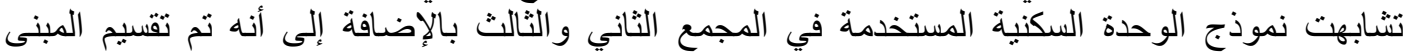

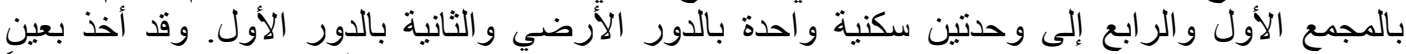

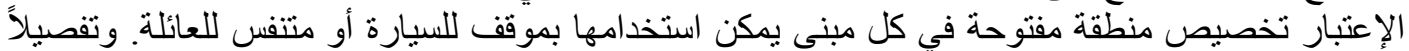

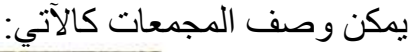

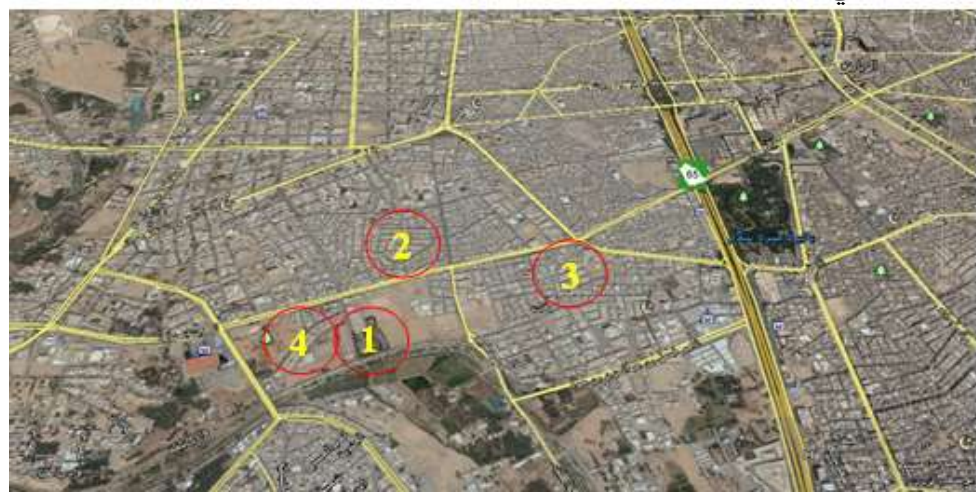

صورة (1): مو اقع المجمعات الأربعة في أحياء منقاربة بمدينة الرياض، المصدر : Google Maps 1.2 المجدع الأول

يقع المشروع بحي سلطانة بمدينة الرياض (صورة 2) و هو مكون من صفين من البلوكات المتو ازية داخل

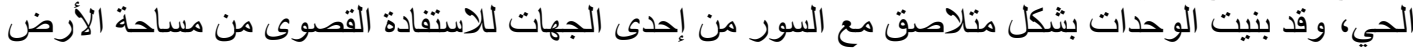

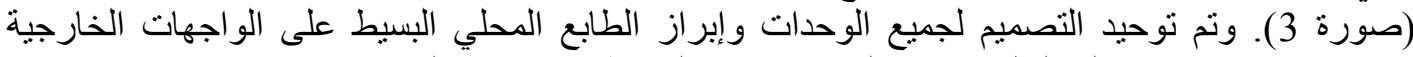
ذستخدمين مو اد غير مكلفة لتقليص قيمة لمشروع قدر المر المستطاع، وتكون المشروع من (122) وحدة سكنية

ذات تصميم واحد موز عة اد على مكلى (61) مبنى.

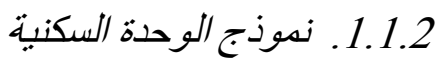

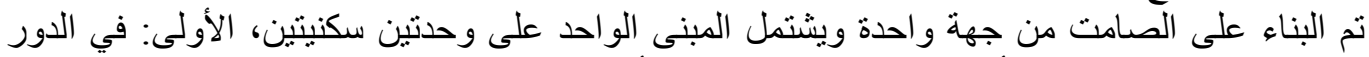

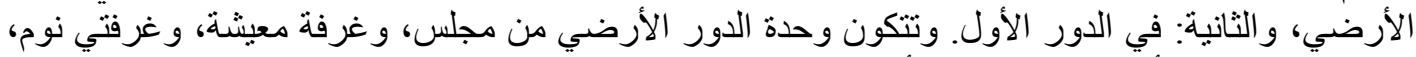

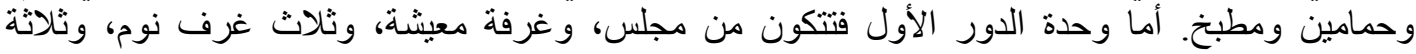




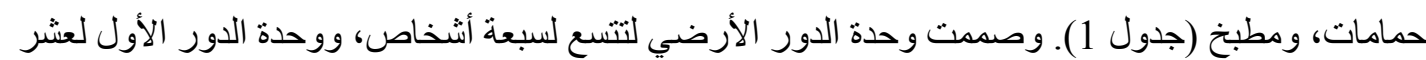

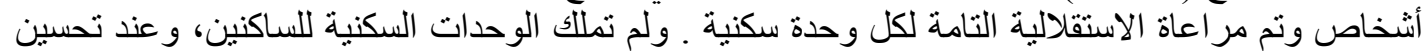

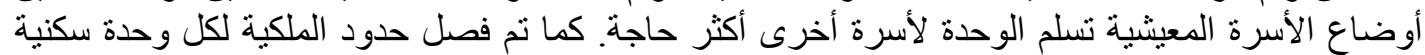
لضمان عدم وجود أماكن مشتركة حتى لا تكون عرضة لاعة للإهمال. (مجلة البناء ، 2000م).

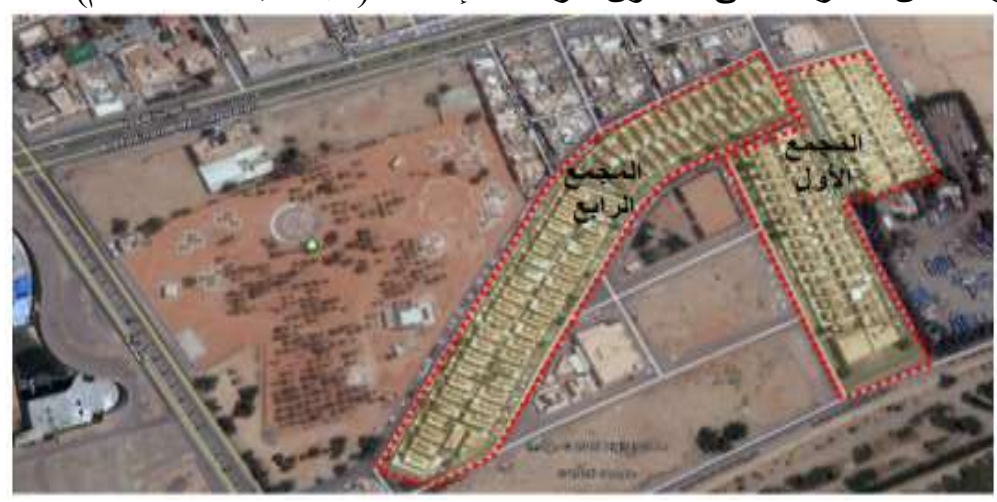

صورة (2): صورة جوية للمجمعين الأول و الرابع ، المصدر : Google Maps

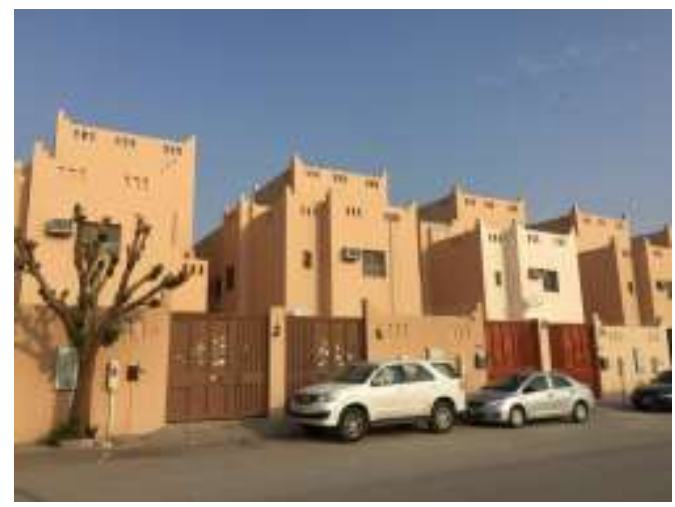

صورة (3): الوحدات السكنية المنفذة في المجمع الأول المصدر : الباحثنان، (التقطت الصورة بـتاريخ 2014/11/28م)

2.2

يقع المشروع على موقع غير منتظم يقرب من شكل المثلث(صورة 4)، وقسم إلى بلوكات منو ازية بحيث تأخذ الوحدات السكنية اتجاهي الشمال و الجنوب (صورة 5. 5). خصص في في وسط المشروع مساحتين إحداهما تضم المسجد وبعض المر افق، و الأخرى تتكون من حديقة وملاعب رياضية التهان، ويتكون المشروع من (124)

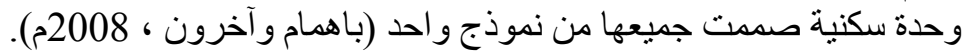

1.2.2 ندوذج الوحدة السكنبية

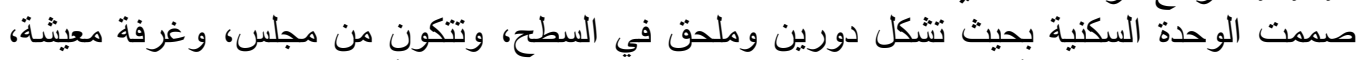
ومطبخ وحمامين في الدور الأرضي، وثثلاث غرف نوم وحمامين في الدور الأول، و وغرفة وحمام في السطح

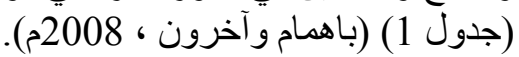


أحمد بن عبداله بن أحدد الغامدي، مساعد بن عبدالهه السدحان، تقويم تصميم الوحدات السكنية في مشاريع جمعية.

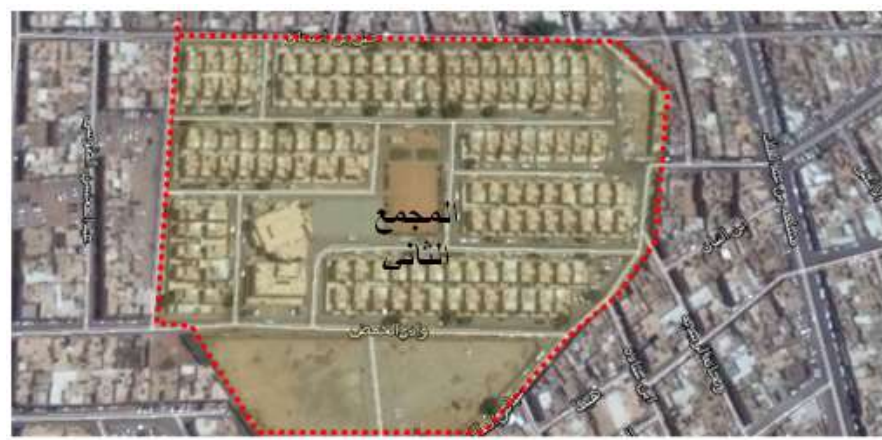

صورة (4): صورة جوية للمجمع الثاني ، المصدر : Google Maps

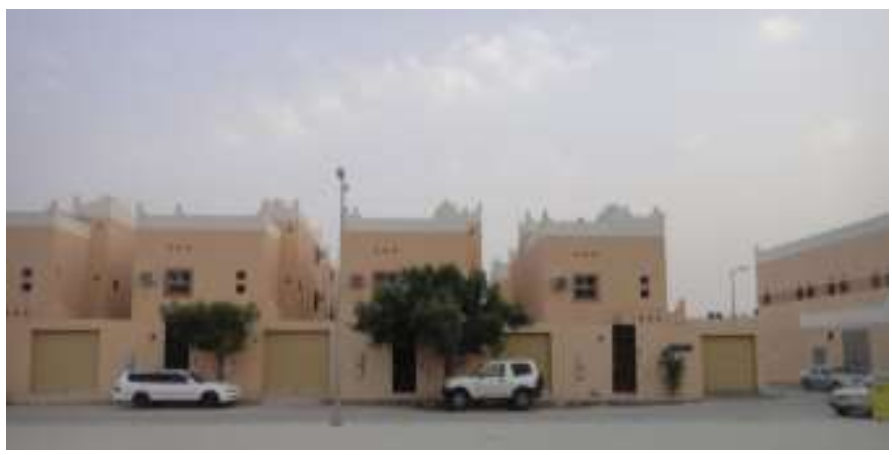

صورة (5): الوحدات السكنية المنفذة في مشروع المجمع الثاني

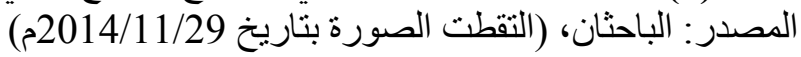

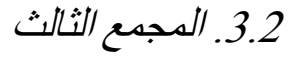

يقع المجمع الثالث بحي الجرادية بمدينة الرياض ويتكون من (77) وحدة سكنية ذات التهن تصميم موحد

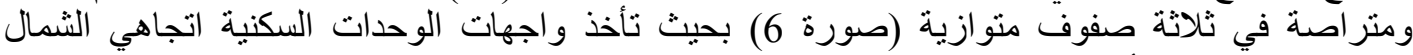

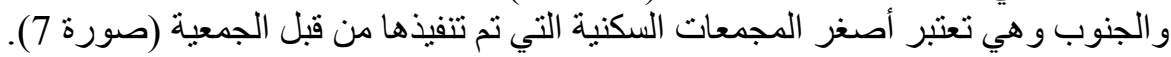

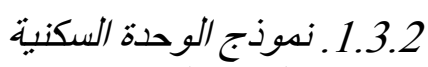

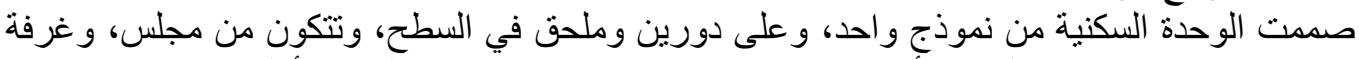

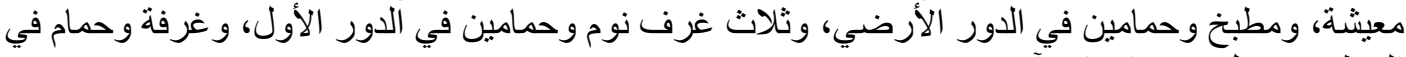
السطح (جدول 1) (باهمام وآخرون ، 2008م).

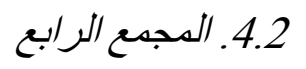

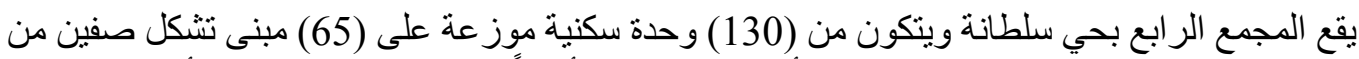

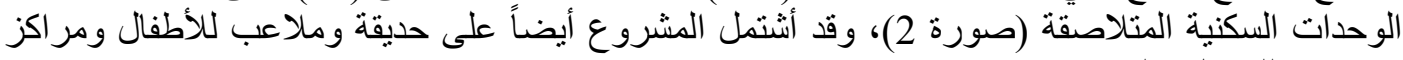
اجتماعية للرجال و السيدات (صورة 8).

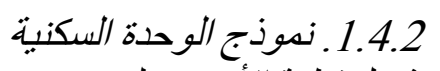

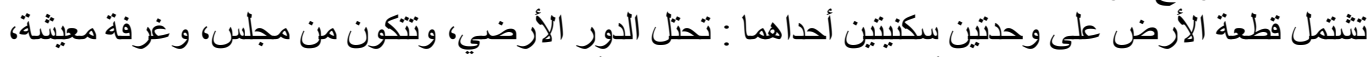

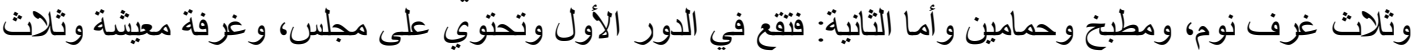

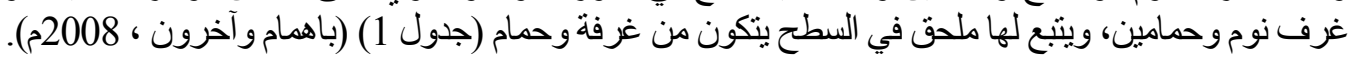




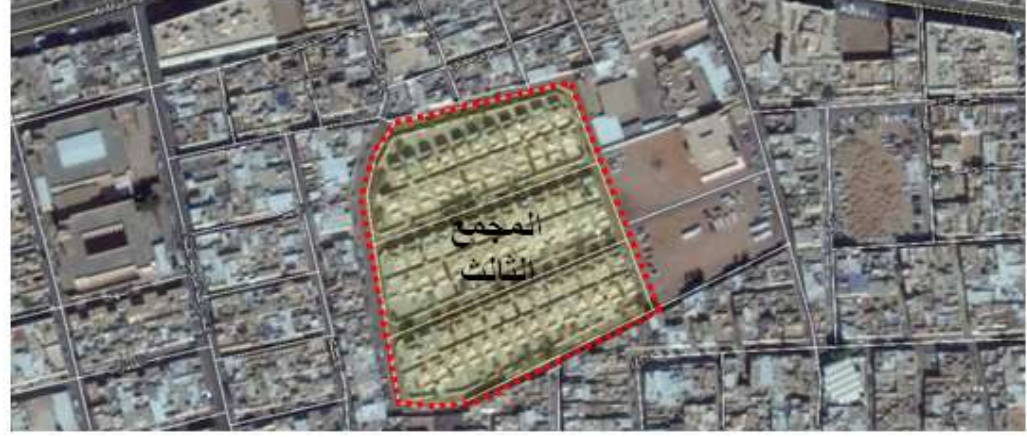

صورة (6): صورة جوية للمجمع الثالث ، المصدر : Google Maps

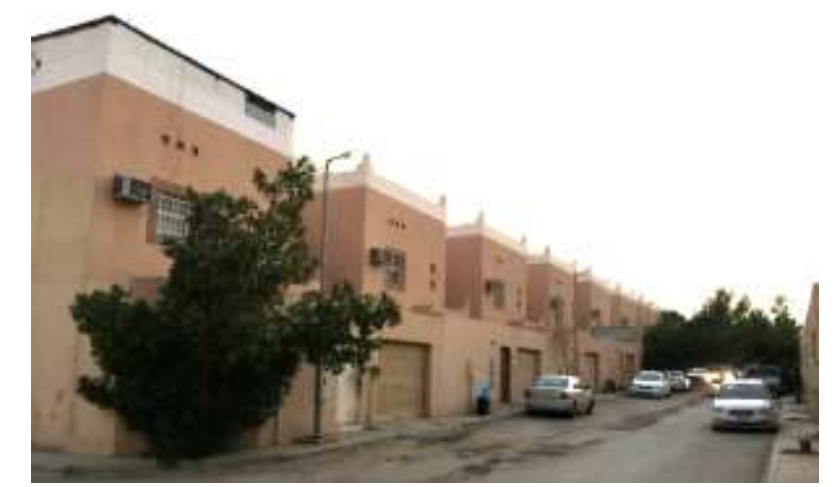

صورة (7): الوحدات السكنية المنفذة في مشروع المجنمع الثالث

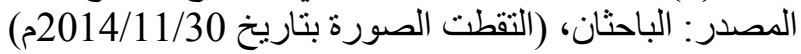

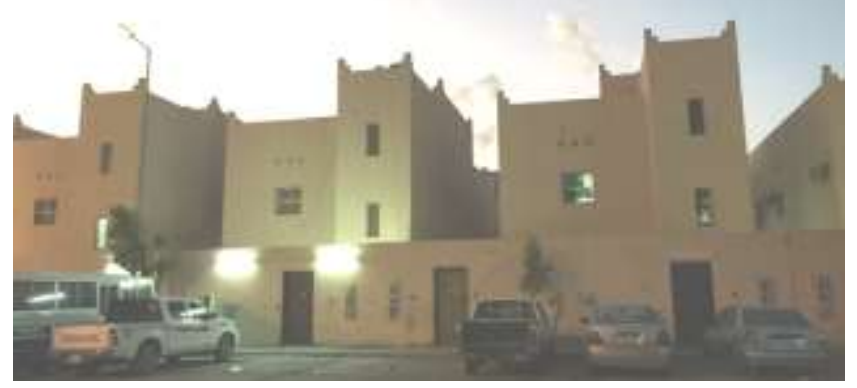

صورة (8) الوحدات السكنية المنفذة في مشروع المجمع الرابع

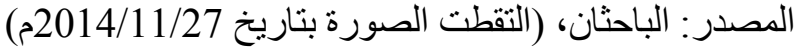

3. تحليل نتائج أداة البحث

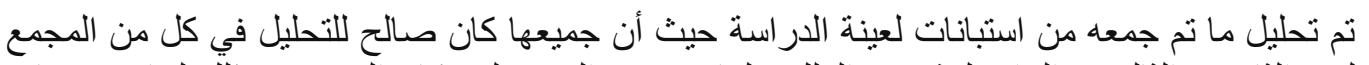

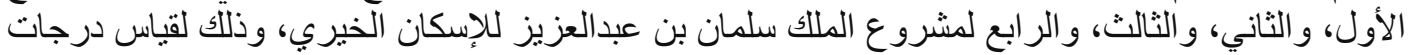

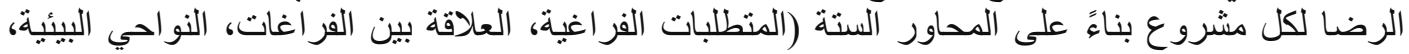

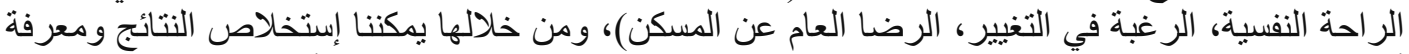

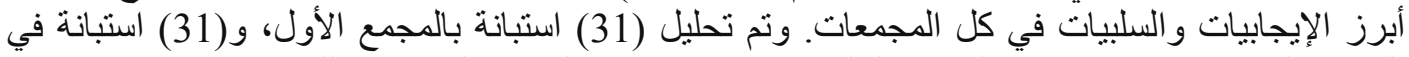

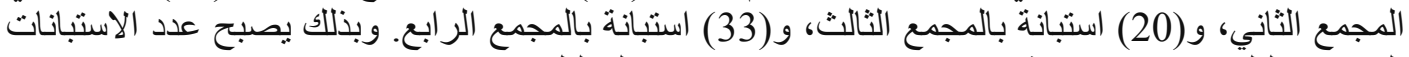
التي تم تحليلها (115) استبانة وقد استخدم برنامج (Excel) لتحليل نتائج هذه الاستبانات. 
أحمد بن عبداله بن أحدد الغامدي، مساعد بن عبدالهه السدحان، تقويم تصميم الوحدات السكنية في مشاريع جمعية. جدول (1): مقارنة بين المجمعات الأربعة لجمعية الملاك سلمان للإسكان التنموي في مدينـة الرياض من

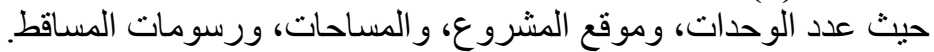
(إعداد الباحثان) ، المصدر : إدارة المشاريع التابعة لجمعية الملاك سلمان للإسكان الخيري

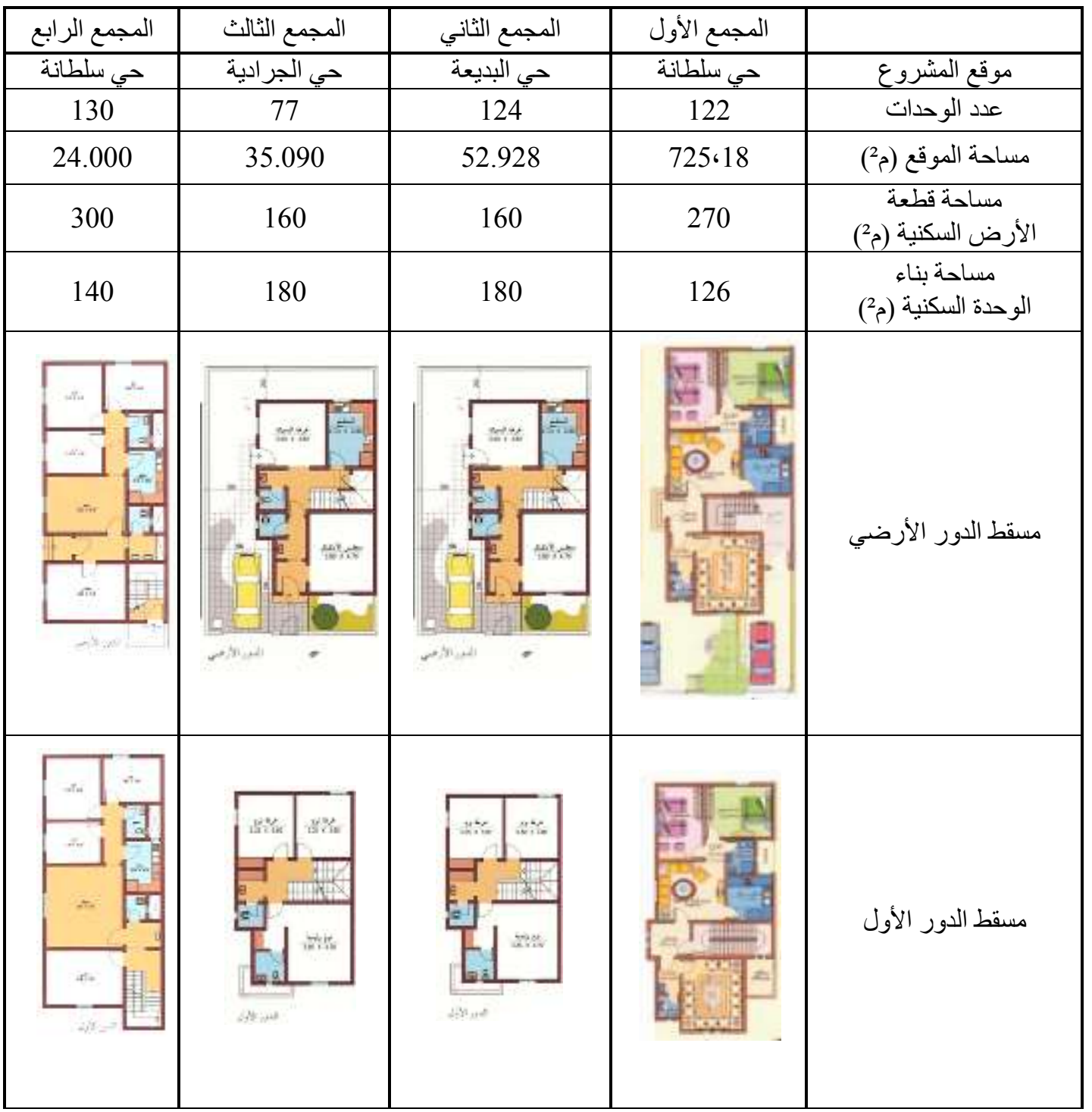

4. دراسة تكوين الأسرة والمعلومات العامة

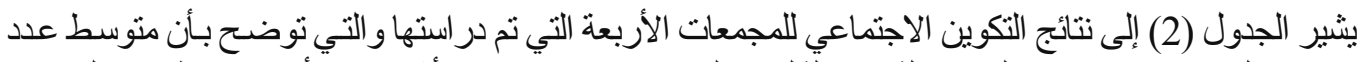

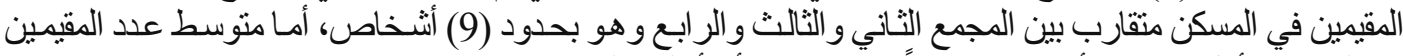

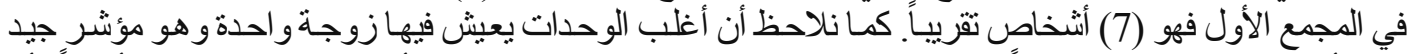

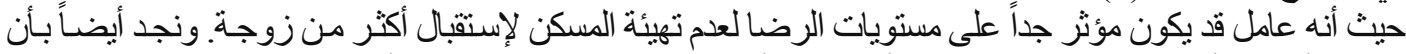

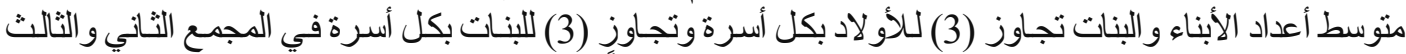

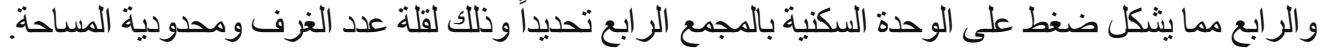


JES, Assiut University, Faculty of Engineering, Vol. 43, No. 2, March 2015, pp. 263 - 281

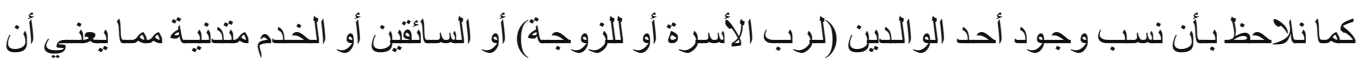

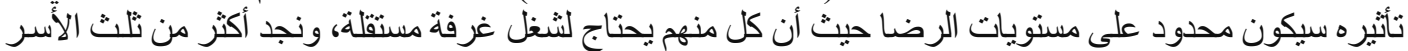

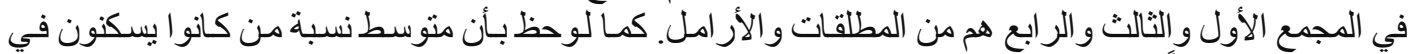

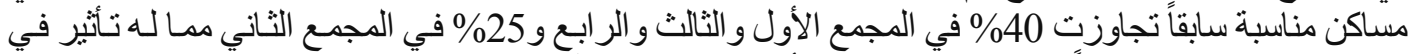

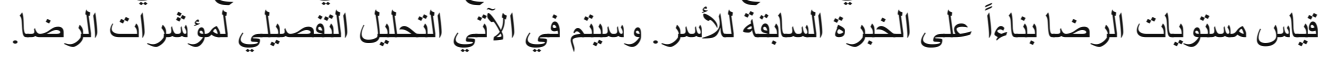

جدول (2): خصائص الأسر المقيمة بالمجمعات الأربعة

\begin{tabular}{|c|c|c|c|c|}
\hline الرابع & الثالثمع & الثانيع & الأولمع & خصائص الأسر المقيمة بالمجمعات الأربعة \\
\hline 9.64 & 9.3 & 9.24 & 7.24 & متوسط عدد المقيمين في المسكن \\
\hline 1.08 & 1 & 1.04 & 1.04 & متوسط عدد الزوجات في المسكن \\
\hline 3.44 & 3.4 & 3.76 & 2.76 & متوسط عدد الأو لاد في المسكن \\
\hline 3.44 & 3.4 & 3.36 & 2.44 & متوسط عدد البنات في المسكن \\
\hline$\% 4$ & 0 & $\% 4$ & 0 & نسبة وجود الو الد أو الو الدة في المسكن \\
\hline$\% 4$ & $\% 5$ & 0 & 0 & عدد سائقين في المسكن \\
\hline$\% 4$ & $\% 15$ & 0 & $\% 8$ & نسبة وجود الخدم في المسكن \\
\hline$\% 4$ & $\% 65$ & $\% 8$ & $\% 28$ & نسبة وجود أفر اد آخرون في المسكن \\
\hline$\% 44$ & $\% 35$ & $\% 4$ & $\% 36$ & نسبة عدد المطلقات والآرامل \\
\hline$\% 4$ & 0 & $\% 3$ & $\% 4$ & نسبة من يستخدم كرسي متحرك \\
\hline$\% 16$ & $\% 15$ & $\% 12$ & $\% 20$ & نسبة وجود ذوي إحتياجات خاصة \\
\hline$\% 4$ & 0 & 0 & $\% 8$ & نسبة من يربي بهائم أو دو اجن \\
\hline$\% 40$ & $\% 40$ & $\% 25$ & $\% 48$ & نسبة من كان مسكنه السـابق مناسب \\
\hline 1.52 & 1.65 & 1.32 & 1.8 & متوسط عدد السيار ات لكل مسكن \\
\hline 9.88 & 7.85 & 8.03 & 13.08 & متوسط عدد الضيوف في المناسبة \\
\hline 3409.4 & 4513.7 & 2951.03 & 3585.6 & متوسط الدخل الشهري (ربال) \\
\hline 3944 & 4161.2 & 3135.87 & 3960 & متوسط الصرف الثهري (ربال) \\
\hline $534.6-$ & 352.5 & $184.83-$ & 374.4 & متوسط صافي الوضع المالي شهرياً (ربال) \\
\hline
\end{tabular}

\section{5. مؤشرات الرضا في المجمعات الأربعة}

تجدر الإشارة إلى أن فياس مؤشرات الرضا اعتمدت على الإجابة على أسئلة الإستبانة المكونة من ثناثنة

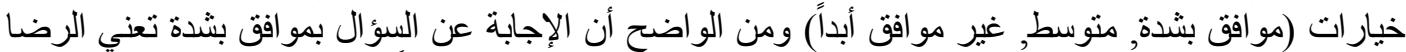

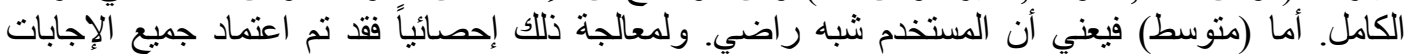

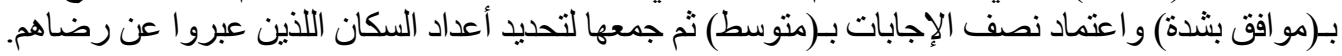

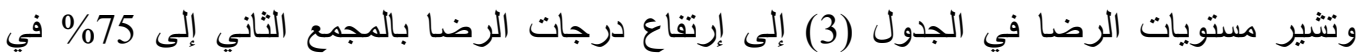

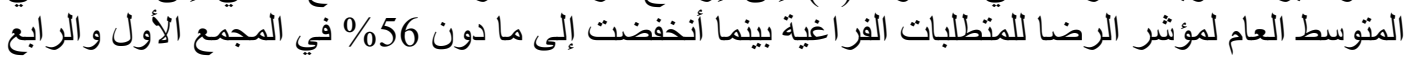

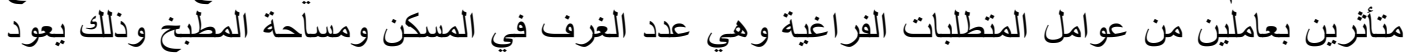

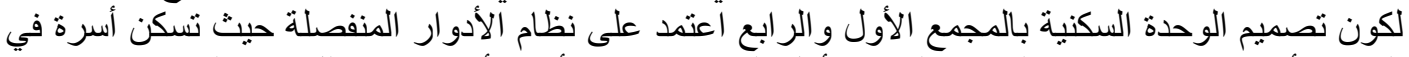

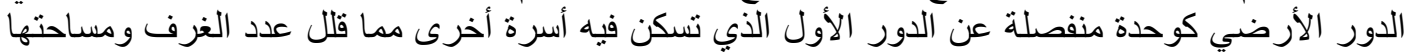

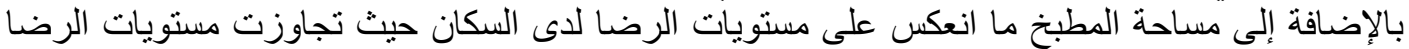
بالمجمعين الثاني و الثالث 61\% 
أحدد بن عبد/له بن أحدد الغامدي، مساعد بن عبد/له السدحان، تقويم تصديم الوحدات السكنية في مشاريع جدعية جدول (3): نسب الرضا للمتطلبات الفر اغية في المجمعات الأربعة

\begin{tabular}{|c|c|c|c|c|c|c|c|c|}
\hline \multicolumn{2}{|c|}{ المجمع الرابع } & \multicolumn{2}{|c|}{ المجمع الثالث } & \multicolumn{2}{|c|}{ المجمع الثاني } & \multicolumn{2}{|c|}{ المجمع الأول } & \multirow{2}{*}{ عناصر الوحدة } \\
\hline النسبة & العدد & النسبة & العدد & النسبة & العدد & النسبة & العدد & \\
\hline$\% 45$ & 15 & $\% 70$ & 14 & $\% 71$ & 22 & $\% 48$ & 15 & عدد الغرف \\
\hline$\% 85$ & 28 & $\% 85$ & 17 & $\% 94$ & 29 & $\% 77$ & 24 & عدد دور ات المياه \\
\hline$\% 36$ & 12 & $\% 40$ & 8 & $\% 58$ & 18 & $\% 42$ & 13 & مساحة الغرف \\
\hline$\% 70$ & 23 & $\% 50$ & 10 & $\% 87$ & 27 & $\% 67$ & 21 & المباه \\
\hline$\% 27$ & 9 & $\% 45$ & 9 & $\% 68$ & 21 & $\% 35$ & 11 & مساحة المطبخ \\
\hline$\% 64$ & 21 & $\% 80$ & 16 & $\% 71$ & 22 & $\% 67$ & 21 & مساحة الحوش \\
\hline$\% 55$ & 18 & $\% 62$ & 12.3 & $\% 75$ & 23.5 & $\% 56$ & 17.5 & متوسط الرضا \\
\hline
\end{tabular}

وتشير مستويات الرضا عن العلاقة بين الفر اغات في الجدول (4) إلى مستويات رضا مرتفعة في جميع

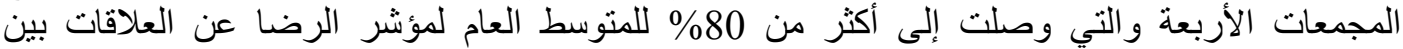

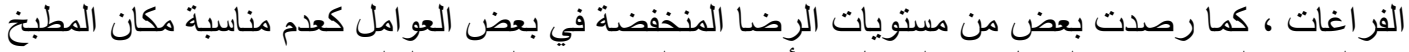

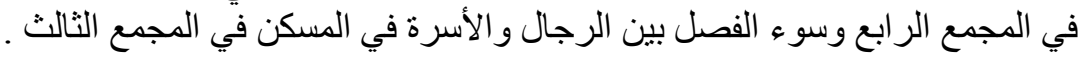
جدول (4): نسب الرضا للعلاقة بين الفر اغات في المجمعات الأربعة

\begin{tabular}{|c|c|c|c|c|c|c|c|c|}
\hline \multicolumn{2}{|c|}{ المجمع الرابع } & \multicolumn{2}{|c|}{ المجمع الثالث } & \multicolumn{2}{|c|}{ المجمع الثاني } & \multicolumn{2}{|c|}{ المجمع الأول } & \multirow{2}{*}{ عناصر الوحدة السكنية } \\
\hline النسبة & العدد & النسبة & العدد & النسبة & العدد & النسبة & العدد & \\
\hline$\% 73$ & 24 & $\% 80$ & 16 & $\% 74$ & 23 & $\% 77$ & 24 & توزيع الغرف \\
\hline$\% 67$ & 22 & $\% 55$ & 11 & $\% 68$ & 21 & $\% 81$ & 25 & والفصلَ بين الرجال \\
\hline$\% 64$ & 21 & $\% 90$ & 18 & $\% 90$ & 28 & $\% 81$ & 25 & مكان المطبخ \\
\hline$\% 91$ & 30 & $\% 95$ & 19 & $\% 90$ & 28 & $\% 84$ & 26 & أماكن دور ات المياه \\
\hline$\% 94$ & 31 & $\% 100$ & 20 & $\% 84$ & 26 & $\% 94$ & 29 & مكان الحوش \\
\hline$\% 78$ & 25.6 & $\% 84$ & 16.8 & $\% 81$ & 25.2 & $\% 83$ & 25.8 & متوسط الرضا \\
\hline
\end{tabular}

وفي الثكل (1) تشير مستويات الرضا عن العناصر المرتبطة بالنواحي البيئية إلى إرتفاع طفيف الإنف

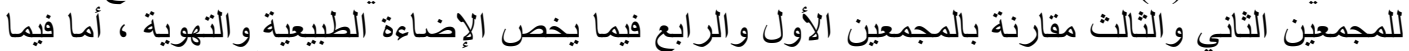

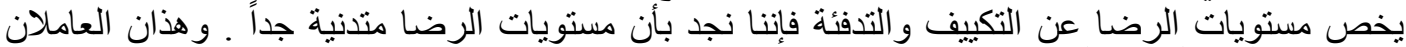

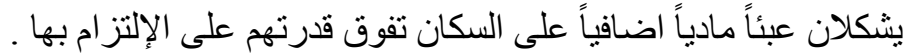

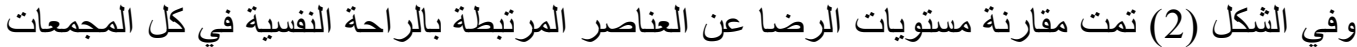

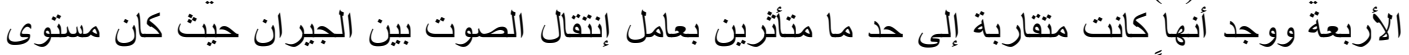

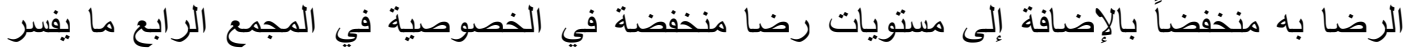

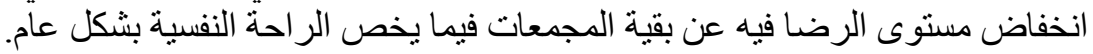
وتشير المقارنة في مستويات الرغبة في التغيير في الجدول (5) إلى إرتفاع منوسط الرضا والريا بالمجمعين

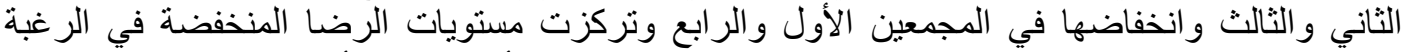

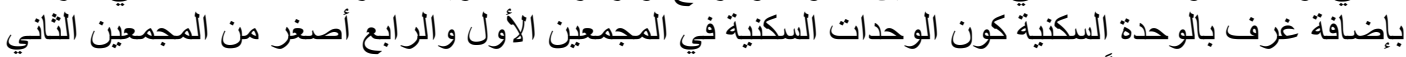
و الثالث كما ذكرنا سابقاً . 


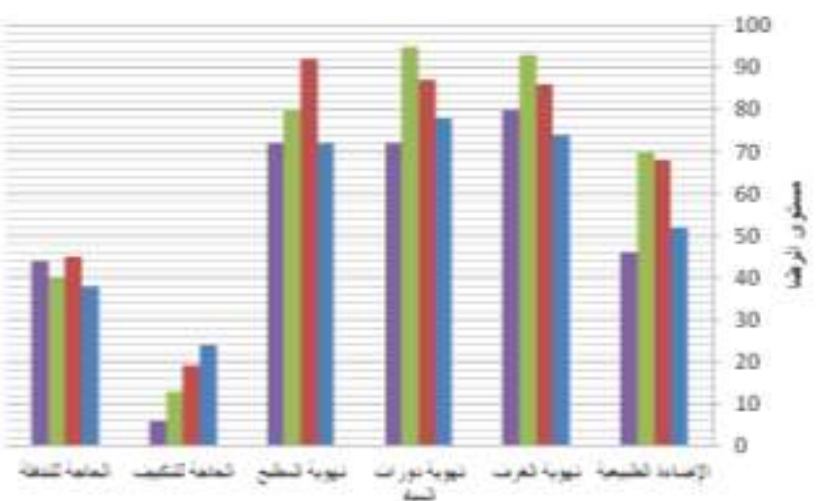

شكل (1): مقارنة مستوى الرضا عن العناصر المرتبطة بالنو احي البيئية

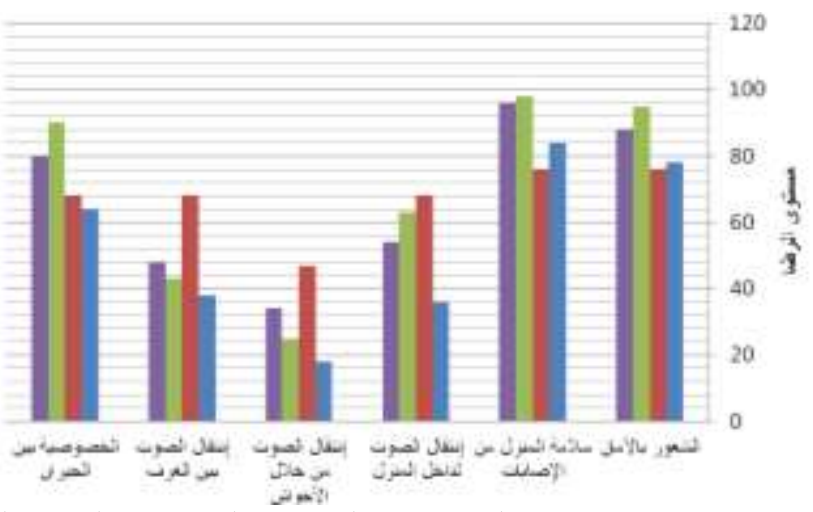

شكل (2): مقارنة مستوى الرضا عن العناصر المرتبطة بالر احة النفسية*

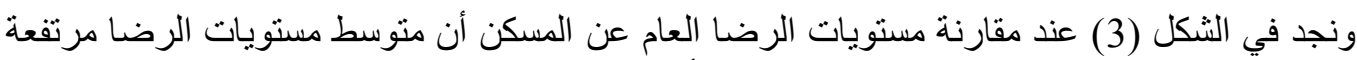

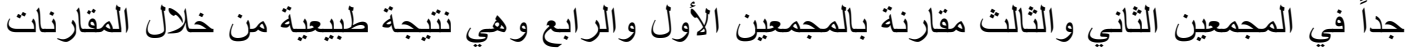

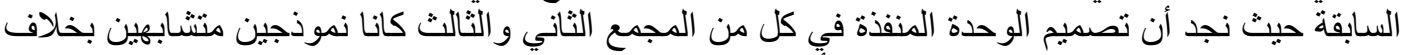

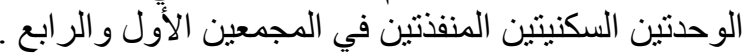
جدول (5): نسب الرضا في الرغبة للتغيير في المجمعات الأربعة

\begin{tabular}{|c|c|c|c|c|c|c|c|c|}
\hline \multicolumn{2}{|c|}{ المجمع الرابع } & \multicolumn{2}{|c|}{ المجمع الثالث } & \multicolumn{2}{|c|}{ المجمع الثاني } & \multicolumn{2}{|c|}{ المجمع الأول } & \multirow{2}{*}{ عناصر الوحدة السكنية } \\
\hline النسبة & العدد & النسبة & العدد & النسبة & العدد & النسبة & العدد & \\
\hline$\% 58$ & 19 & $\% 70$ & 14 & $\% 68$ & 21 & $\% 55$ & 17 & لون الواجهة \\
\hline$\% 67$ & 22 & $\% 90$ & 18 & $\% 74$ & 23 & $\% 68$ & 21 & شكل الواجهة \\
\hline$\% 18$ & 6 & $\% 25$ & 5 & $\% 39$ & 12 & $\% 19$ & 6 & الرغبة في إضافة غرف* \\
\hline$\% 58$ & 19 & $\% 60$ & 12 & $\% 45$ & 14 & $\% 55$ & 17 & الرغبة في إجر اء تغيير ات داخلية* \\
\hline$\% 64$ & 21 & $\% 85$ & 17 & $\% 77$ & 24 & $\% 48$ & 15 & توحيد شكل المسكن في المجمع \\
\hline$\% 53$ & 17.4 & $\% 66$ & 13.2 & $\% 61$ & 18.8 & $\% 49$ & 15.2 & متوسط الرضا \\
\hline
\end{tabular}




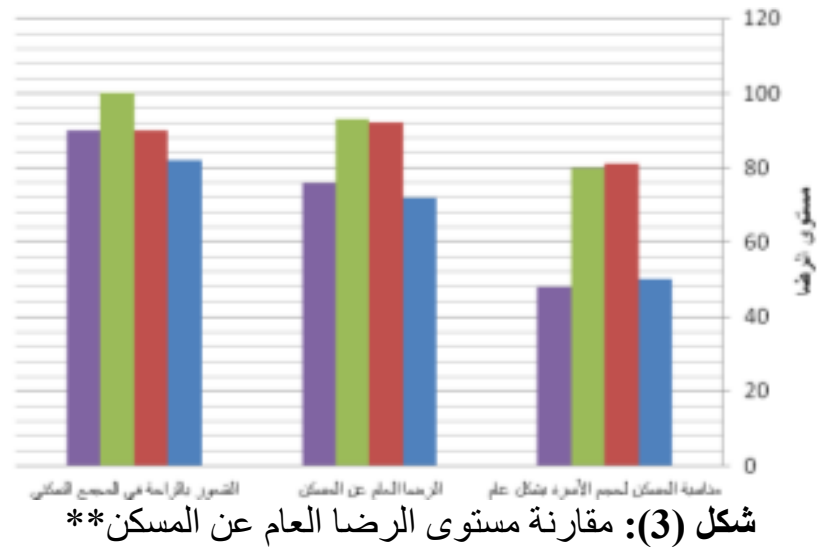

6. نتائج الدراسة

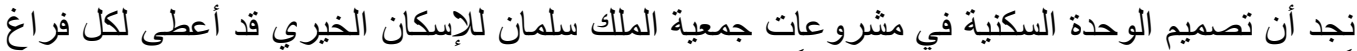

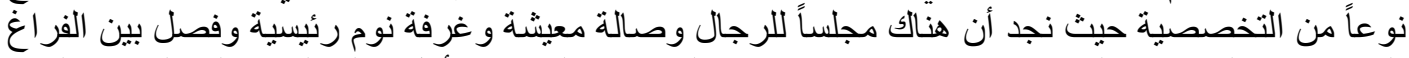

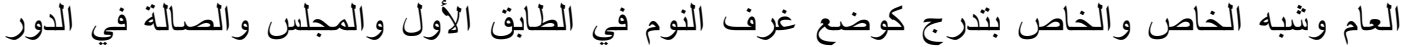

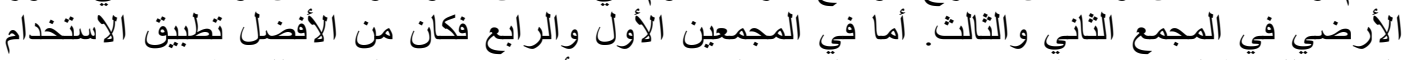

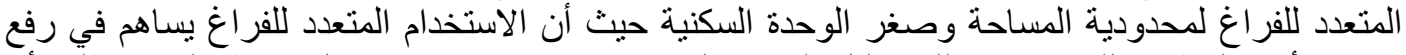

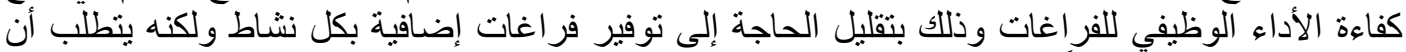

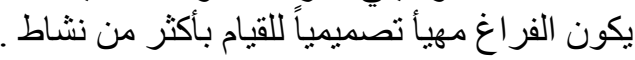

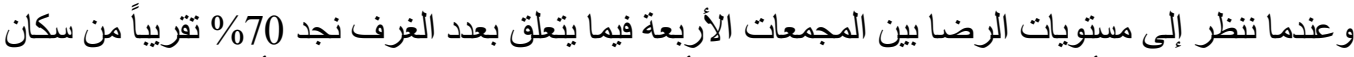

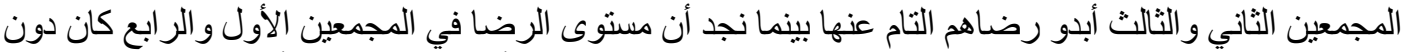

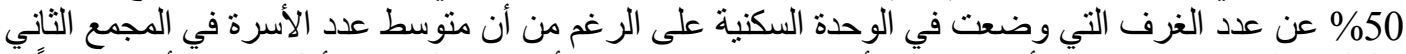

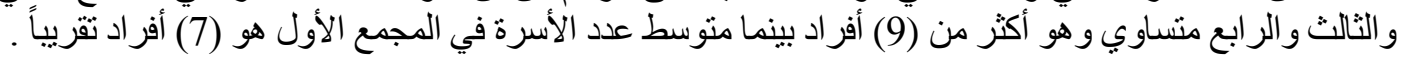

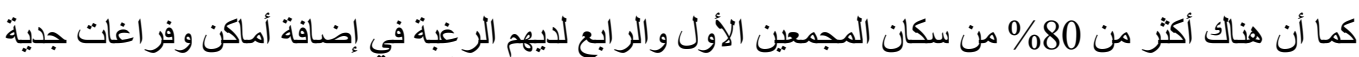

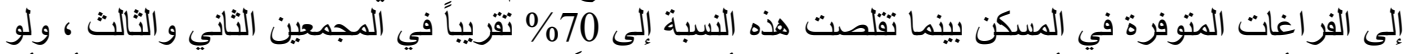

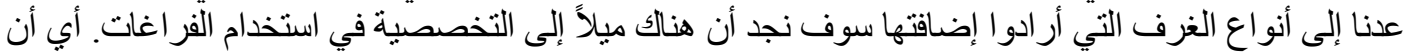

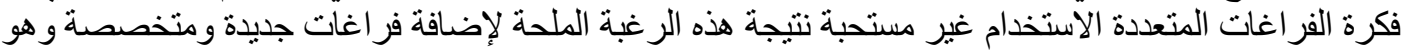

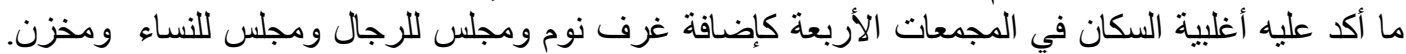

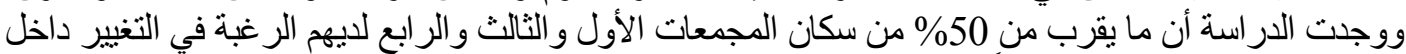
الوحدة السكنية، وهو أمر مهم جداً يؤثر بشكل واضح على على إختبار النظم الإنشائية عند بناء المساكن.

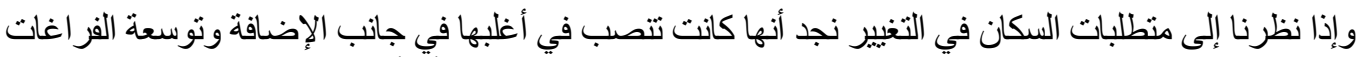

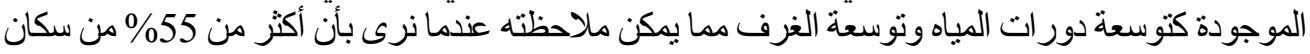

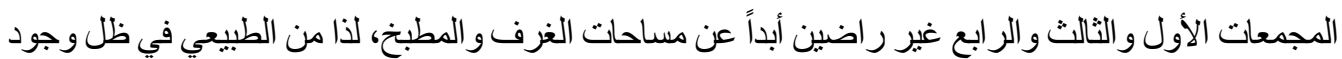

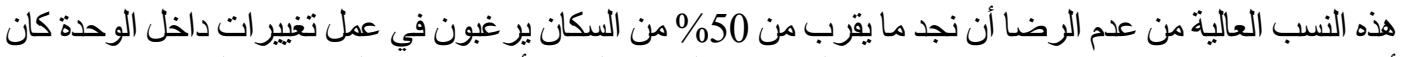

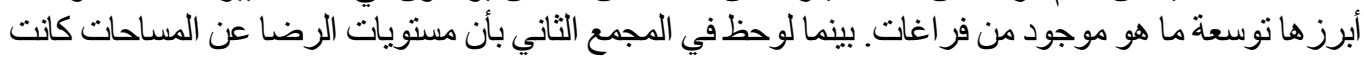

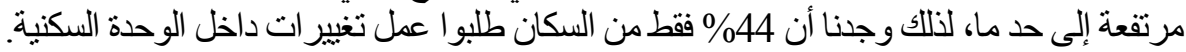

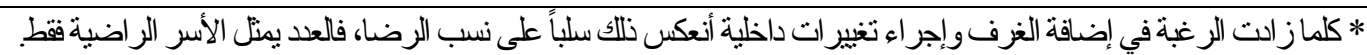

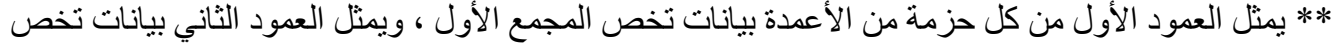

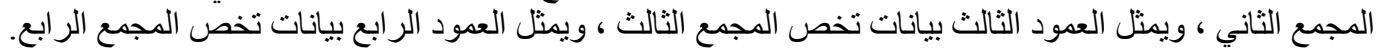




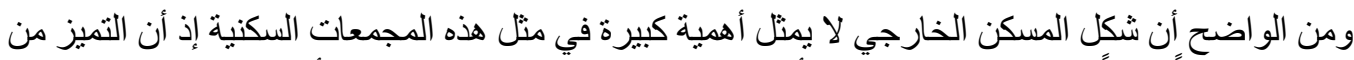

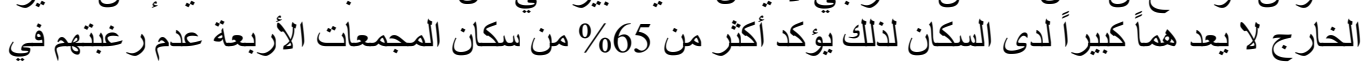

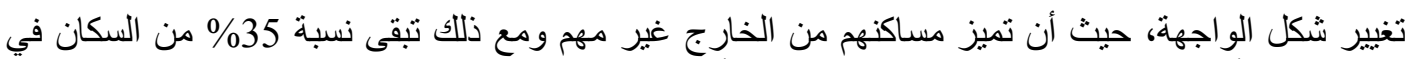

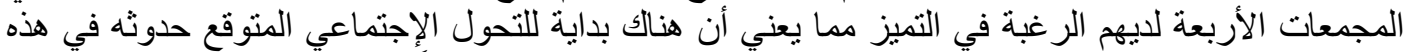

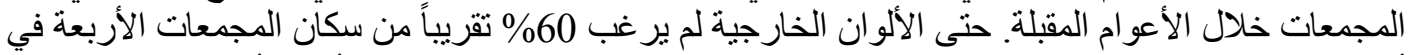

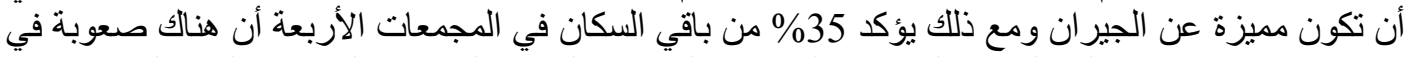

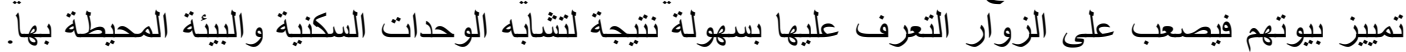

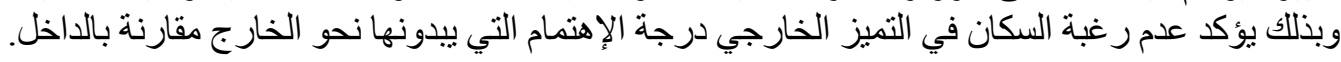

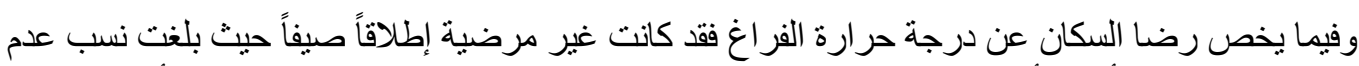

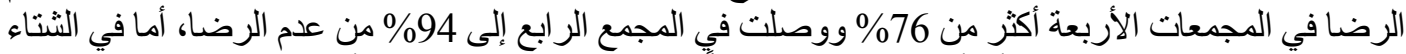

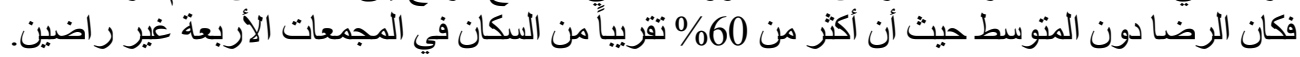

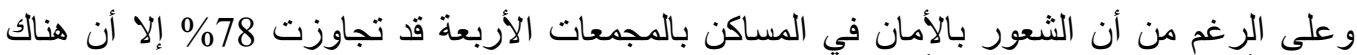

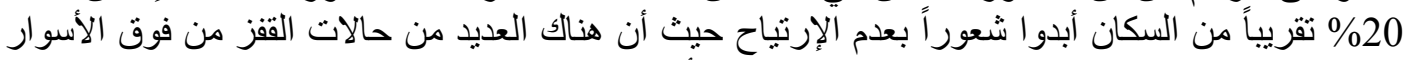

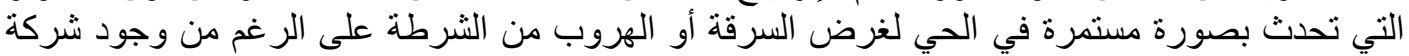
أمنية مسؤولة عن حر اسة المجمع السكني.

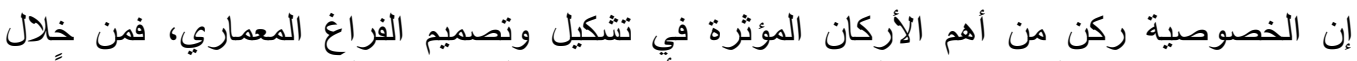

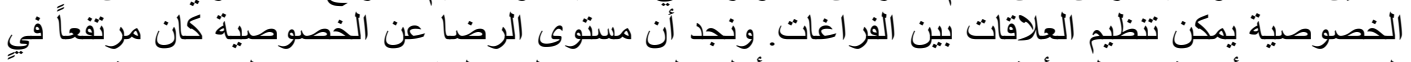

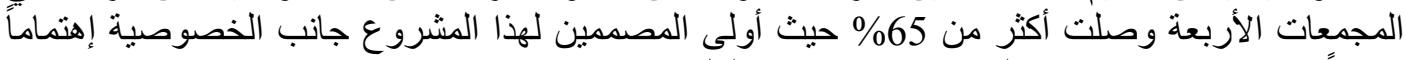
خاصاً حيث تم تصميم فتحات النو افذ في إتجاه و احد لكل وحدة سكنية.

\section{7. - 1 توصيات الاراسة}

توصي الدراسة ببعض التوصيات التي من شأنها أن تحسن من جودة السكن في مشرو عات الإسكان الخيري، أههها:

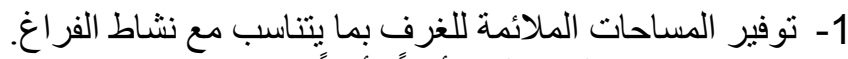
2- 2- مرونة الإمتداد المستقبلي رأسياً وأفقياً. 3- مر اعاة المعالجات المناخية في تصميم الوحدة السكنية.

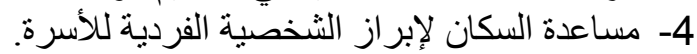

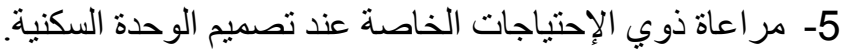

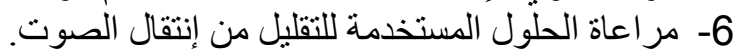

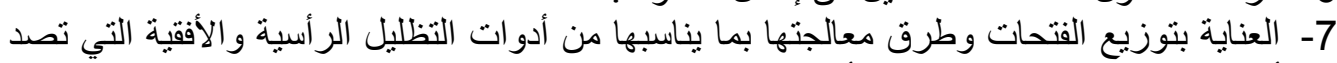

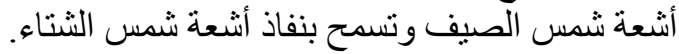
8- - يجب إحتر ام خصوصية الجير ان.

9- إحترام التسلسل الفر اغي داخل المسكن و عدم الخلط بين الفراغ العام وشبه الخاص و الخاص.

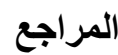

[1] القباني ، محمد عبدالعزيز : الرضا السكاني لذوب الدخل المحدود ، در اسة حالة ضاحية العريجا في مدينة

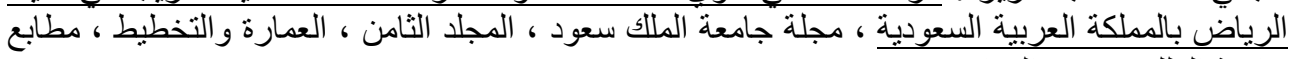

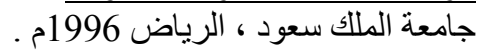
[2] آل الثيخ ، هشام بن عبداللطيف : تقييم و اقع الإسكان الخيري ، رسالة ماجستير غير منشورة ، جامعة الملك

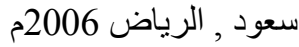

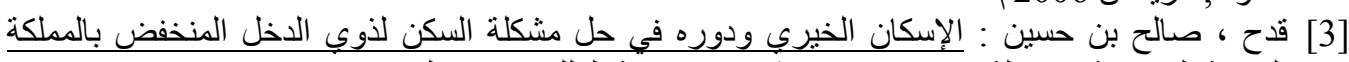

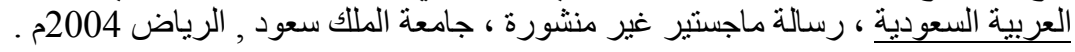


أحدد بن عبداله بن أحدد الغامدي، مساعد بن عبد/له السدحان، تقويم تصديم الوحدات السكنية في مشاربيع جمعية....

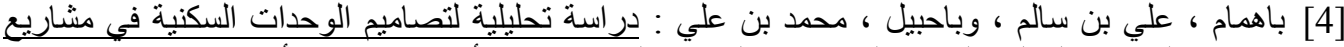

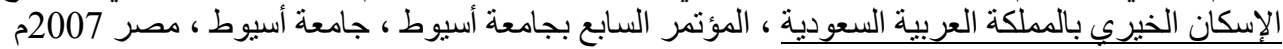

[5] Salleh ، Ghani : Residential and Neighborhood Satisfaction in Private Low-Cost Housing ‘Housing Symposium 3 ، Riyadh 2007 .

[6] Preiser، Wplfgang ‘ Rabinowitz، Harvey \& White، Edward : Post Occupancy Evaluation ،Van Nostrand Reinhold ، New York ، 1988 .

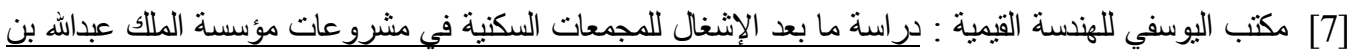

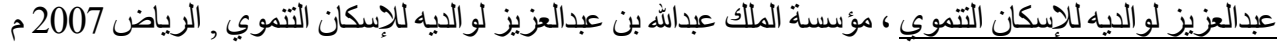

[8] Carp، Frances : Long-Range Satisfaction with Housing ، Gerontologist (Oxfordjournals.org) ، Berkeley, February 1975

[9] Amole، Dolapo : Residential satisfaction in students' housing ، Journal of Environmental Psychology ، Vol. 29 , Amsterdam ,2009

[10] Abul Mohit، Mohammad ، Ibrahim، Mansor ‘ Rashid، Yong : Assessment of Residential satisfaction in newly designed public low-cost housing in Kuala Lumpur، Malaysia ‘Habitat International ‘Vol. 34 , Amsterdam ، 2010

[11] Ukoha، Onyekwere \& Beamish، Julia : Assessment of Residents' Satisfaction with Public Housing in Abuja ‘ Nigeria ، Habitat International ، Vol.21 ، Amsterdam ‘1997

[12] Tas، Nilufer ، Cosgun، Nilay \& Tas، Murat : A qualitative evaluation of the after earthquake permanent housings in Turkey in terms of user satisfaction - Kocaeli Gundogdu Permanent Housing model ، Building and Environment ، Vol.42 ، Oxford,2007

[13] Altas، Nur Esin \& Ozsoy، Ahsen : Spatial Adaptability and Flexibility as Parameters of Users Satisfaction for Quilty Housing ، Building and Environment ، Vol.33 ، Oxford,1998

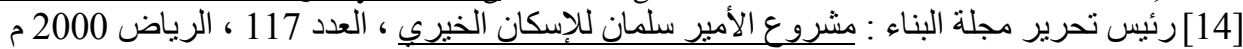

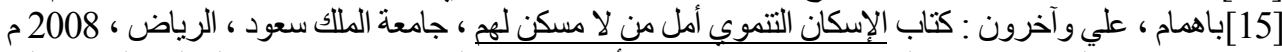

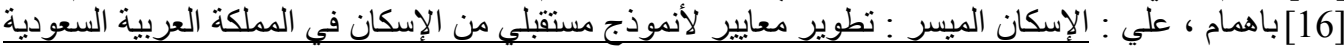

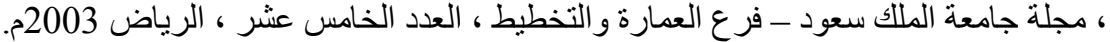

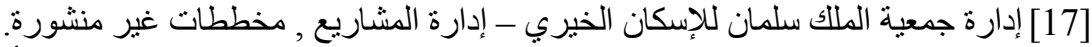

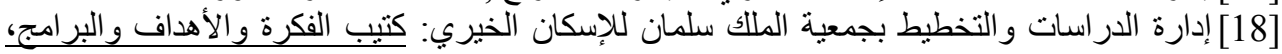
الرياض 2005م 


\title{
DESIGN EVALUATION FOR HOUSING UNITS AT PRINCE SALMAN * ASSOCIATION FOR CHARITABLE HOUSING IN RIYADH
}

\begin{abstract}
Through the large number of charity housing projects that have been implemented in Riyadh over the past years it was necessary to conduct an evaluation study to determine the satisfaction of beneficiaries for the design of the housing units in these charitable projects. King Salman Association for charity Housing has been selected as a case study for this study due to its largest number of charitable housing projects constructed in Riyadh.

This research comes due to differences in the design of charity housing units in spite of the similarity of beneficiaries characteristics' and the study aims to measure the degree of satisfaction of necessary needs for those who dwell in the charity housing units in order to know the basic requirements that effects on the level of satisfaction so that it can be provided in future residential units.

The study was conducted to measure the satisfaction of beneficiaries for the design of their residential units by comparing between the association's projects in Riyadh (the first compound the second compound، the third compound، and the fourth compound). The research methodology is divided into two parts: first, the literature review of techniques and methods to measuring satisfaction in housing projects in both global and local cases. Second is a field study by comparing the satisfaction of the four residential compounds that have been run in the city of Riyadh by comparing scores of satisfaction among the various housing units models. The study showed results to be taken into consideration when designing future housing units as the number of spaces ، the area and its relations with each other' visual efficiency to interfaces، environmental aspects of the unit، psychological comfort، and privacy.
\end{abstract}

* Prince Salman Charitable Housing Association was founded in 1997 when Salman bin Abdul Aziz was the Prince of Riyadh. Before the publication of this research, the people swore allegiance to the Salman bin Abdul Aziz as the king of Saudi Arabia and the official name of the Association became King Salman Charitable Housing Association. 
أحدد بن عبداله بن أحدد الغامدي، مساعد بن عبد/له السدحان، نقوبم تصديم الوحدات السكنبة في مشاربيع جعبية. شكل (4): الصفحة الأولى من نموذج الإستبانة

\begin{tabular}{|c|c|c|c|c|}
\hline 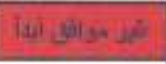 & ingin & $\tan 30$ & \multicolumn{2}{|l|}{ المقسم الأول : المنطلبات المزراغية } \\
\hline & & & 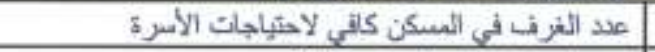 & 1 \\
\hline & & & ملد الحمامبك في المسكن كافية & 2 \\
\hline & & & مساحات المزرت في المسكن مئلسية & 3 \\
\hline & & & | مساحات الحمامات في المسكن منلبية & 4 \\
\hline & & & مساحة المطبخ في المسيكن مثاعبة & 5 \\
\hline & & & |مسلحكت الأحو ائي كالية & 6 \\
\hline & & & 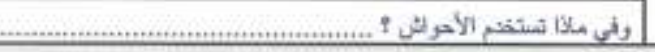 & \\
\hline$f \begin{array}{ll}1 \\
1\end{array}$ & bing & 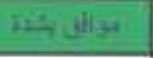 & \multicolumn{2}{|l|}{ القصم الثشاني : العلاقة بين المزر اغات } \\
\hline & & & |توزيع الغز في مئاسبة & 1 \\
\hline & & & 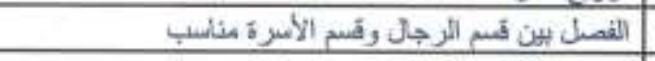 & 2 \\
\hline & & & كان المطبخ شنائب & 3 \\
\hline & & & |المكن الحمالبك منلبية & 4 \\
\hline & & & المسكن الأحواثن مئلمبة & 5 \\
\hline intilo & bingin & istity & \multicolumn{2}{|l|}{ القسم الثاتك : التواحي البيكبة } \\
\hline & & & 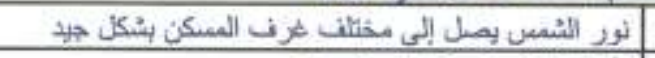 & 1 \\
\hline & & & 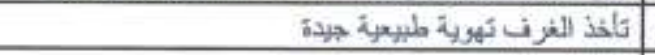 & 2 \\
\hline & & & 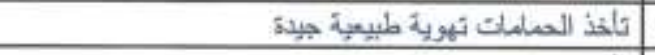 & 3 \\
\hline & & & 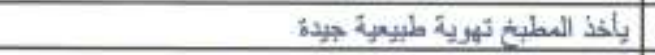 & 4 \\
\hline its & 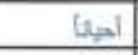 & Lils & |اسنطبع أن الجلس في مرفة دون مكيث في الصنيف & 5 \\
\hline بن & 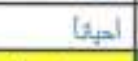 & بن & 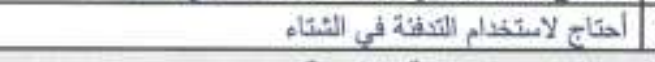 & 6 \\
\hline 4 thas $x=$ & (en & بول & \multicolumn{2}{|l|}{ الثَم الرابع : الرزاحة الثفسبية } \\
\hline & & & |أشعر أن مسكني آمن & 1 \\
\hline 1,0 & Ey & $\omega_{1}$ & | نحدث إصدابك في الميزل & 2 \\
\hline 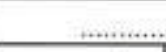 & & & 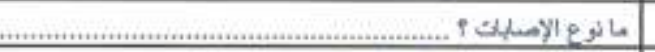 & \\
\hline ناتراً & [يل & Lis & 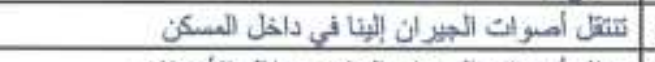 & 3. \\
\hline 1,0 & لحينأ & Leila & 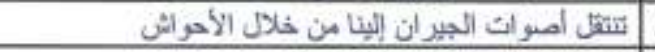 & 4 \\
\hline 1,0 & 罗 & ائع & المصوت ينتلتل بين غرن المسكن & 5 \\
\hline & & & | بكُشت المجير أن المسكن & 6 \\
\hline 住 & مُونط & 5x औो & \multicolumn{2}{|l|}{ المسب الخاسس : الزر غبة في التفير } \\
\hline & & & 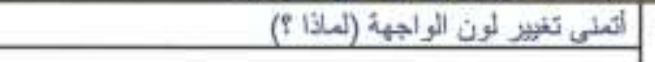 & 1 \\
\hline & & & & \multirow{2}{*}{2} \\
\hline & & & 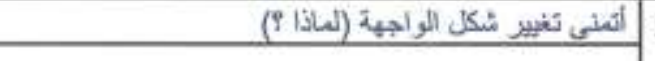 & \\
\hline & & & ألميني إضافة غرن (النكر ها) & \multirow[t]{2}{*}{3} \\
\hline & & & & \\
\hline & & & 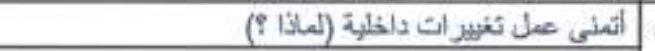 & \multirow[t]{2}{*}{4} \\
\hline & & & & \\
\hline & & & 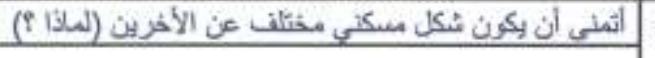 & 5 \\
\hline 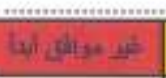 & مثربط & $3 \sin _{3}=0$ & قسم السادص : الرضنا العام عن العسكن & \\
\hline & & & 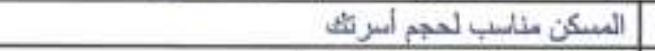 & 1 \\
\hline & & & 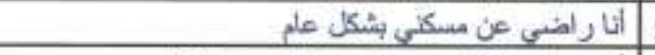 & 2 \\
\hline & & & | أنسر بالّر لحة لوجودي في هذا الهجمع المبكثي & 3 \\
\hline
\end{tabular}


شكل (5): الصفحة الثانية من نموذج الإستبانة

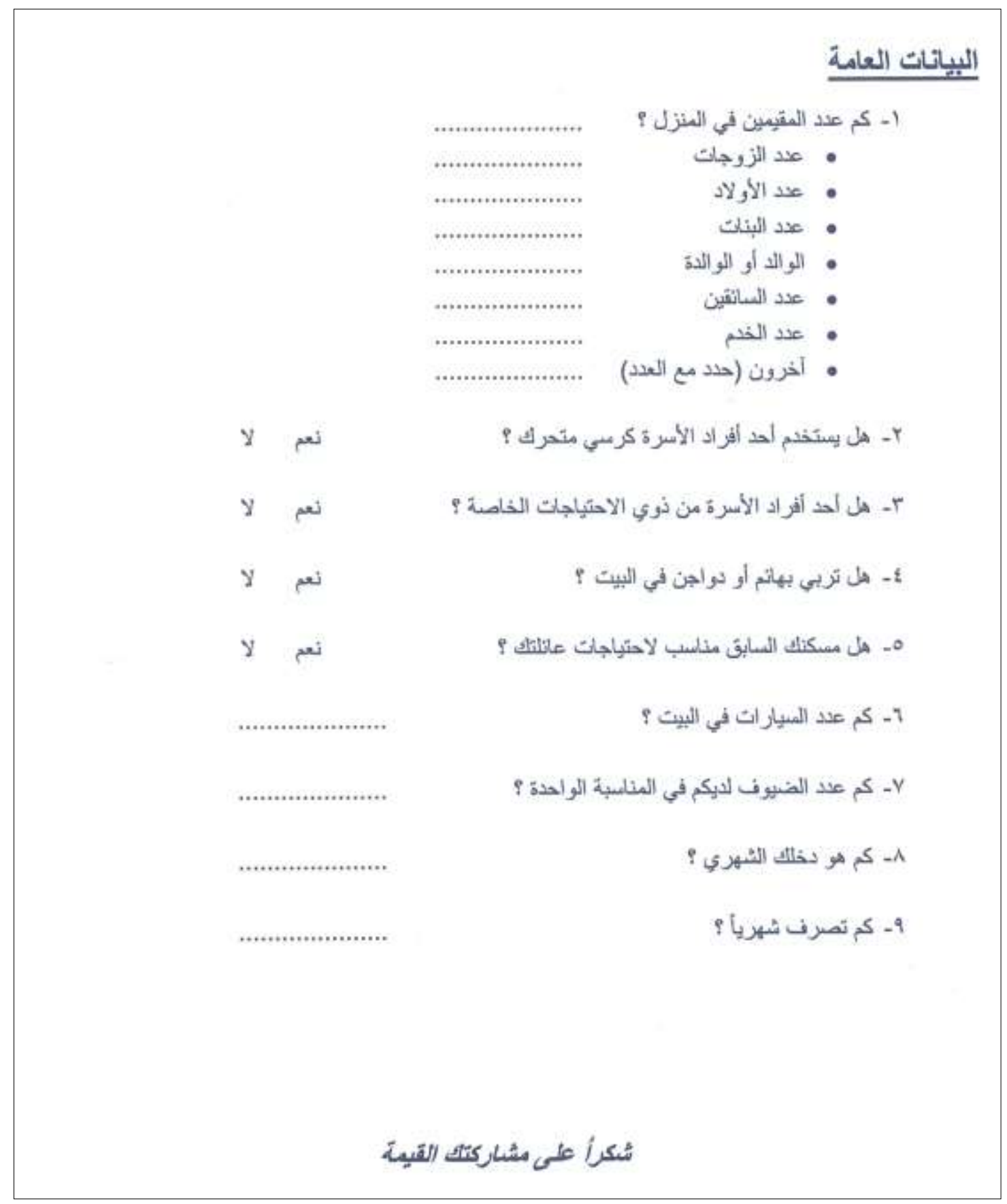

